\title{
EL USO DEL AGUA EN ÉPOCA ROMANA EN EL EBRO MEDIO. ESTUDIO DE CASOS EN LA RIOJA Y ÁREAS LIMÍTROFES
}

\author{
Adrián Calonge Miranda \\ Universidad del País Vasco / Euskal Herriko Unibertsitatea \\ adrian.calonge@ehu.eus
}

\begin{abstract}
RESUMEN: El siguiente texto busca analizar las diferentes estructuras hidráulicas que se han conservado en la zona riojana del Ebro Medio De esta manera se van a describir las infraestructuras que formaban parte de un ciclo artificial del agua de captación, transporte y distribución: presas, acueductos o sistemas de evacuación. También se va a abordar el uso del agua con fines industriales o lúdicos en las termas, urbanas o rurales. Por último, se hablará sobre la religión y el derecho aplicados al agua.
\end{abstract}

Palabras clave: agua, La Rioja, infraestructuras, religión, derecho, época romana.

\section{THE USE OF WATER IN ROMAN TIMES IN THE MIDDLE EBRO. CASE STUDY IN LA RIOJA AND NEIGHBORING AREAS}

\begin{abstract}
The following text analyzes the hydraulic structures conserved in La Rioja. The infrastructures that were part of the water collection, transport and distribution cycle (dams, aqueducts or evacuation systems) will be described. The use of water for industrial or recreational purposes will also be addressed thanks to the pipes or thermal baths. Finally, the relationship between religion, law and water will be discussed.
\end{abstract}

Keywords: Water, La Rioja, infraestructures, religion, law, roman time.

Recibido: 20 de abril de 2020

Aceptado: 17 de junio de 2020 


\section{Introducción}

Durante la historia, el agua ha sido un elemento vital para la supervivencia del ser humano. Tiene su propio ciclo natural desde que precipita hasta que se evapora para volver a comenzar. En época romana, se creó un ciclo artificial usando la ingeniería. Este posibilitaba su captación, distribución y su utilización mediante azudes, presas, acueductos, canales, fuentes, termas o complejos industriales.

El agua también tenía una importante dimensión social que trasciende a las infraestructuras hidráulicas. Los cauces fluviales y sus valles tuvieron una clara influencia en la planificación y construcción del entramado viario romano. La religiosidad rodeó a las aguas ejemplificada en el culto a las ninfas o divinidades indígenas cuyos restos han sobrevivido en forma de templos o en la epigrafía. El disfrute y la política se trataban en los baños, las cualidades sanadoras de las aguas termales eran aprovechadas y la jurisprudencia se ocupó del tratamiento, la protección y el mantenimiento de los canales, las riberas y los cursos para hacerlos viables para su uso y navegación. Por lo tanto, hay que hablar de una dimensión social que rodeaba al líquido elemento

Los objetivos del presente trabajo son facilitar un panorama completo de las infraestructuras hidráulicas de cronología romana que se han descubierto en el área de estudio. Así mismo, se busca tanto la descripción de estos restos de carácter arqueológico, su posterior interpretación y la relación con su uso y el alcance social que estos tenían.

El área de estudio propuesta es el actual territorio riojano. El cauce principal es el Ebro que, según Plinio, era navegable hasta Vareia (Varea, Logroño, La Rioja $)^{1}$. Su valle configura la entrada natural al interior peninsular desde la costa mediterránea. Así mismo, sus tributarios por la margen derecha son cursos secundarios como el Oja-Tirón, el Najerilla, el Iregua, el Leza-Jubera, el Cidacos y el Alhama-Linares. Estos ríos también constituyen uniones naturales entre el Ebro y la Meseta atravesando la cordillera alpina del Sistema Ibérico y entre el Ebro y los Pirineos a través de la actual Comunidad Foral. Así mismo se han introducido ejemplos de yacimientos de la Comunidad Foral de Navarra y del País Vasco con el objetivo de ofrecer un panorama completo de las infraestructuras hidráulicas que se construyeron en La Rioja.

1. "Es claro que el recorrido de esta vía principal está determinado por la navegabilidad del Ebro, el cual, retomando el texto de Plinio, "era navegable desde el oppidum Vareia durante un trayecto de 260.000 pasos" (Plin. NH 3.3.21). Esta combinación de río y calzada sería de gran ayuda para la navegación fluvial, ya que, en determinadas épocas del año ésta era, por razones climatológicas, más difícil e incluso imposible" (Castillo, M. J., "Ríos y calzadas en el valle del Ebro: la influencia de la navegación en el trazado de las vías", Czeguhn, Waser, wege, wissen auf der iberischen halbinselvom Römischen Imperium bis zur islamischen Herrschaft. Nomos 2016, pp. 63-64). 


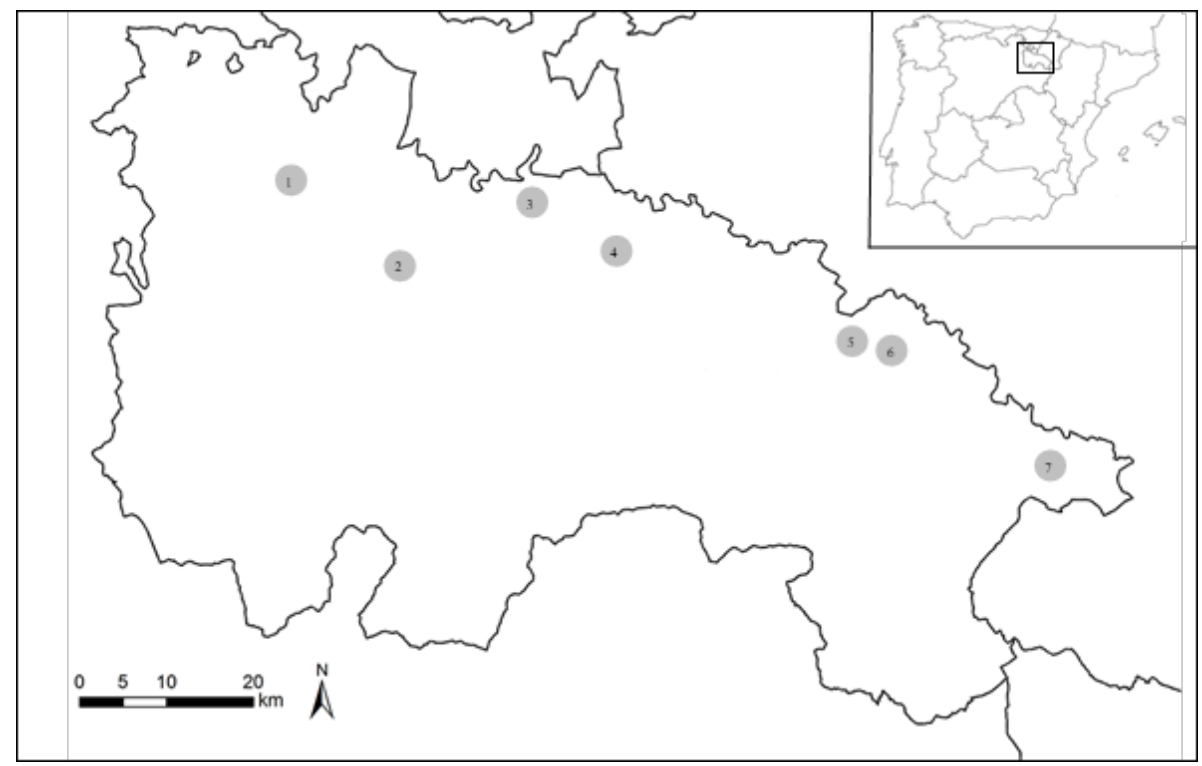

Figura 1. Área de estudio y detalle de los lugares mencionados en La Rioja (1. Tirgo, 2. Tricio, 3. Varea (Logroño), 4. Valles del Leza y del Jubera; 5. Pradejón; 6. Calahorra y 7 Alfaro) (Elaboración propia).

La zona del Ebro Medio fue una de las regiones de la Península Ibérica donde se produjo la fundación de un enclave romano: Graccurris en el 179 a. C. y fue testigo del final de las guerras numantinas, los enfrentamientos fratricidas entre romanos con la participación de Sertorio o la intervención de César. Con el establecimiento del nuevo poder imperial en Roma, se produjeron varias promociones jurídicas en la región, especialmente bajo el patrocinio de las dos primeras dinastías reinantes con ejemplos bajo el cetro de Augusto (Calagurris Iulia, Calahorra), Tiberio (Gracurris, Alfaro; y Cascantum, Cascante) o con los emperadores flavios (Vareia, Logroño; Andelos, Mendigorría; y Cara, Santacara). El acceso a la categoría privilegiada de estas civitates, propició la ejecución de un programa de monumentalización que las dotó de nuevos servicios, entre ellos los que se servían del líquido elemento. Las etapas de dinamismo económico trajeron consigo también la construcción de infraestructuras hidráulicas también en el ámbito rural. Todas estas edificaciones se mantuvieron en uso, al menos, cuatro siglos.

El artículo se divide en 7 partes incluyendo esta introducción. El criterio seguido ha sido predominantemente funcional y siguiendo el ciclo artificial ya aludido. El segundo punto versa sobre las presas y azudes usados para la captación del agua tanto para el aprovechamiento urbanos como para labores de 
regadío. Su conducción y distribución aglutina la siguiente parte diferenciando los acueductos y los sistemas internos urbanos incluyendo las aguas negras. El cuarto capítulo se ocupa del disfrute del líquido elemento en las construcciones más representativas como son los complejos termales y su uso en los sistemas industriales de transformación, especialmente los alfares. El antepenúltimo punto se encarga de la dimensión social en la influencia que la hidrografía y sus valles ejercieron en el trazado de las vías de comunicación terrestre, así como la jurisprudencia y la religión aplicada al agua.

La cuestión sobre el uso del agua en época romana en La Rioja es un tema que ha sido tratado de manera puntual y referido a los restos de cada una de las infraestructuras, tanto en escritos que los tratan de manera específica como en obras de historia de carácter general. Mención aparte merecen los trabajos de Rosa Aurora Luezas Pascual sobre el municipium Calaguris lulia que engloban los diferentes conjuntos hidráulicos de la actual Calahorra² ${ }^{2}$

\section{Captación}

\subsection{Aprovechamiento urbano}

Los acueductos de Vareia y el de la sierra de La Hez, cuyo destino era Calagurris lulia (Calahorra), posibilitaban que ambas ciudades pudieran disponer de agua limpia y ambas tenían su origen en azudes de derivación que se ejecutaron en el manantial localizado junto a Puente Madre (Logroño-Villamediana) para el primer caso $^{3}$ y en las corrientes de agua menores de la cara norte de la sierra en el segundo ${ }^{4}$. No se tiene constancia a día de hoy de la existencia cisternas u otros medios de captación como pozos.

\subsection{Infraestructuras para regadío}

Al sur del territorium de Calagurris lulia, se construyó una presa de 176.29 metros repartidos en tres alineaciones $(87.50,56.48$ y $32.31 \mathrm{~m}$ de longitud

2. Luezas, R. A. y Andrés, G., "Calahorra. Obras hidráulicas en el municipium Calagurris Iulia". Estrato. Revista riojana de arqueología 10 (1999), pp. 28-37.

3. Un azud derivaba el agua de un pequeño torrente que discurría aguas abajo del actual Puente Madre (Villamediana de Iregua) (Martínez, J. y Gallego, R., "II. Vareia en el universo romano: de la sumisión a la integración. 5. Morfología del enclave vareyense", Espinosa, "Vol.1: Antigüedad", Sesma, Historia de la Ciudad de Logroño. Logroño 1994, p. 164).

4. Se desconoce qué pequeño curso de agua era el inicio de la conducción, aunque se tiene que ubicar cerca del barranco de San Julián, donde afloran los primeros restos del acueducto (Pascual, M. P., "Abastecimiento de agua a Calagurris" en Arqueología de Calahorra: miscelánea. Calahorra 1991, pp. 58-60). 
cada una) en el paraje de la Degollada, junto a la yasa homónima. El método de construcción de las dos primeras pantallas es similar: una zapata de cimentación de sillares con $2.80 \mathrm{~m}$ de base y 3.30 de altura. Sobre esta se comenzó a realizar la presa mediante un doble paramento de sillares perfectamente encuadrados que esconde un núcleo de hormigón. Todo este conjunto tiene una altura media por encima de la cota del terreno de entre 3.24 y 3.48 metros y una anchura de $2.80 \mathrm{~m}$. La tercera alineación era completamente diferente pues tenía una anchura de 3.35 metros y una ejecución realizada mediante una estructura de cantos rodados. Se ha creído que pudo ser un aliviadero. También tenía un canal de desagüe con una longitud conservada de $3.50 \mathrm{~m}$ y una sección del canal de $0.54 \times 1.30 \mathrm{~m}$ que se situaba entre la primera y la segunda pantalla atravesando la planta de la presa. Para poder reforzar la estabilidad de toda la infraestructura, se tuvieron que realizar estructuras en forma de contrafuertes o un espaldón. En el caso calagurritano se hizo un espaldón de tierras aguas abajo de la presa realizada con capas de arcillas, gravas, cantos rodados y areniscas y hay indicios de contrafuertes. Esta presa creaba un embalse con una capacidad de $1.4 \mathrm{hm}^{3}$ y esta lámina de agua se lograba gracias al uso de los manantiales y escorrentías de la zona. La función principal era la acumulación de agua para regar una superficie estimada de 2000 hectáreas en la zona noreste de la centuriación de la ciudad. La fecha de construcción y uso de esta infraestructura hidráulica es altoimperial ${ }^{5}$.

El río Alhama bordea y articula el territorium de Graccurris y fue un cauce altamente intervenido en época antigua con, al menos, dos conjuntos monumentales: el Sotillo y el Burgo. Se trata de obras singulares que incluían varias estructuras incluyendo una presa, un ninfeo y un puente realizadas de manera conjunta. El Sotillo fue la más antigua ya que se realizó a finales del periodo republicano, pero colapsó en algún momento entre el siglo I y principios del siglo ${ } \mathrm{II}^{6}$. El Burgo, por su parte, se construyó justo en ese momento y se desconoce si entró en servicio de manera contemporánea al otro conjunto o si se levantó para sustituirlo ${ }^{7}$.

5. Tampoco se descarta que pudiera haber un aporte extra con una derivación desde el Cidacos por lo que se levantó un azud de derivación, hoy desaparecido (Cinca, J. L., "La presa romana de La Degollada (Calahorra, La Rioja)". Kalakorikos 17 (2012), pp. 337-348).

6. Sus restos abandonados se convirtieron en una cantera para conseguir material pétreo ya desde época antigua (Hernández, J. A., Ariño, E., Martínez, J. M. y Nuñez, J., "La presa y el ninfeo del Sotillo (Alfaro, La Rioja): un conjunto monumental en la De Italia in Hispanias". Zephyrus: revista de prehistoria y arqueología 52 (1999), pp. 258-260).

7. Era una obra de mayor calidad y más reforzada que la que había colapsado en el término de El Sotillo (Hernández, J. A., Ariño, E., Martínez, J. M. y Nuñez, J., "Contribución al estudio de las presas y ninfeos hispanos: el conjunto monumental del Burgo (Alfaro, La Rioja)". Zephirus: revista de prehistoria y arqueología 51 (1998), pp. 233-236). 
La presa de El Sotillo está conservaba de una manera muy deficiente. Se trataba de una pantalla recta de la que ha llegado hasta nosotros una longitud de 33.28 metros y una altura de $2.65 \mathrm{~m}$. Es un muro de opus quadratum cuidadosamente labrados y colocados sobre un lecho de cantos rodados preparados a tal efecto ${ }^{8}$.
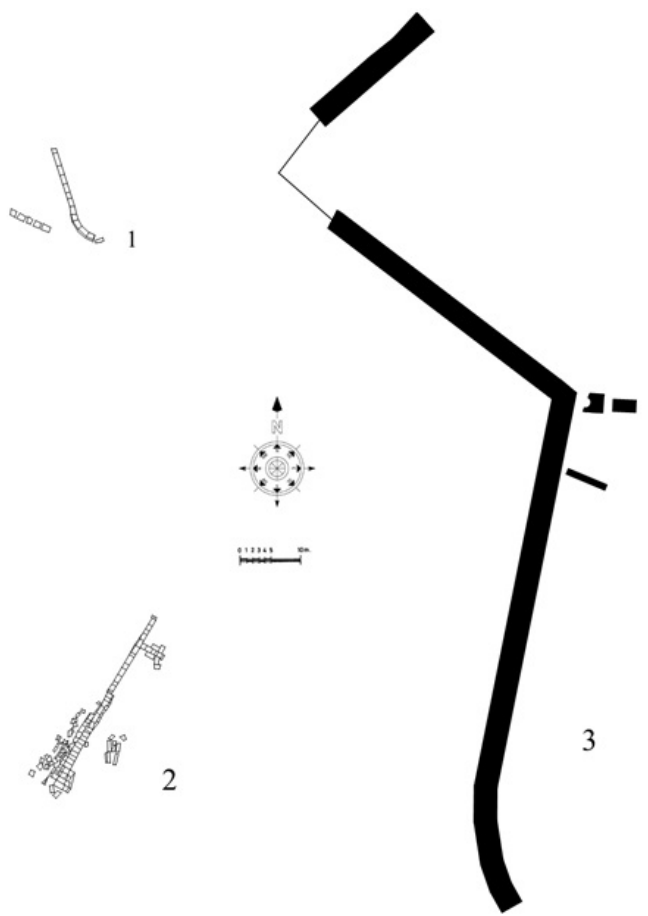

Figura 2. Presas de (1) El Burgo (Alfaro, La Rioja), (2) El Sotillo (Alfaro, La Rioja) y (3) La Degollada (Calahorra, La Rioja) (Elaboración propia a partir de

(1) Hernández, J. A., Ariño, E., Martínez, J. M. y Nuñez, J., "Contribución al estudio de las presas y ninfeos... pp. 222-223; (2) Hernández, J. A., Ariño, E., Martínez, J. M. y Nuñez, J., "La presa y el ninfeo... pp. 242-243 y (3) Cinca, J. L., "La presa romana de La Degollada... p. 337).

La presa de El Burgo, por su lado, conserva parte de su estribo izquierdo y, según testimonios orales, también podía haber restos en la margen derecha. Se ha conservado una pantalla recta oblicua al río de 5.02 m y luego describía

8. Hernández, J. A., Ariño, E., Martínez, J. M. y Nuñez, J., “La presa y el ninfeo del Sotillo ... pp. 241-245. 
una curvatura para hacerla perpendicular al cauce alcanzando los $6.42 \mathrm{~m}$ de longitud. La anchura máxima es de 2.40 y la altura conservada es de 2.24 aunque se piensa que pudo llegar a los 6 metros, al menos, en la parte central. La presa se construyó con un núcleo interno de opus caementicium con presencia de cantos rodados mientras que la cara exterior se ejecutó con sillares de arenisca con juntas selladas con argamasa para mejorar su estanqueidad ${ }^{9}$. Dejando la dimensión religiosa de los ninfeos para el apartado quinto del presente trabajo, estos conjuntos monumentales ayudaban al cruce del río mediante sus puentes y, a su vez, las presas creaban láminas de agua que debieron ser utilizadas para poder regar la centuriación de Graccurris ${ }^{10}$.

\section{Sistemas de distribución: acueductos y suministro urbano}

\subsection{Acueductos}

La conducción del agua desde las zonas de captación hasta su lugar de uso se realizaba mediante acueductos de los que se conservan indicios de tres en el área de estudio propuesta. No tienen una estructura tan monumental como los ejemplos de Segovia o las diferentes infraestructuras hidráulicas que daban servicio a Emerita Augusta, pero emplearon diferentes soluciones constructivas según su origen, trazado y funcionalidad.

El primero de los ejemplos es la conducción que daba servicio al enclave de Vareia. Se trata de una infraestructura de transporte de agua que tiene su origen cerca del actual Puente Madre (Logroño-Villamediana de Iregua) ${ }^{11}$. Se planteó siguiendo las curvas de nivel hacia el norte hasta llegar a la ciudad con una longitud aproximada de 1.100 metros, aunque se desconoce parte de su recorrido. En la zona sur de Varea, en el polígono industrial de La Portalada, se exhumaron restos del canal. Se trata de cajas de piedra impermeabilizadas con hormigón hidráulico de $36 \mathrm{~cm}$ de altura y una anchurs de 29 con espigas en sus extremos para su correcto ensamblaje. La pendiente media es del $0.54 \%$, y tenía un caudal estimado de $150 \mathrm{l} / \mathrm{s}$. Se tiene constancia de la presencia de piscinae limariae para remansar y decantar el agua. Pese a su prolongado uso, se piensa que un cubo de arenisca con una entrada lateral y una salida por la cara inferior y una capacidad de más de 900 litros pudo formar parte de estas estructuras que posibilitaban que el agua Ilegase limpia a su destino. El castellum aquae debía encontrarse no muy lejos de las termas ${ }^{12}$. La función de esta conducción era dar

9. Hernández, J. A., Ariño, E., Martínez, J. M. y Nuñez, J., "Contribución al estudio de las presas y ninfeos hispanos... pp. 222-225.

10. Ariño, E., Hernández, J. A., Martínez, J. N. y Nuñez, J., "Graccurris: conjuntos monumentales en la periferia urbana: puentes, presas y ninfeos". Graccurris 4 (1995), pp. 248-250.

11. Martínez, J. y Gallego, R., "II. Vareia en el universo romano... p. 164.

12. Martínez, J. y Gallego, R., "II. Vareia en el universo romano... p. 165. 
servicio a los habitantes del enclave urbano y a las actividades industriales que se han constatado cerca de la ciudad como alfares, establecimientos agropecuarios, industria metalúrgica, etc. Se construyó a lo largo del siglo I y se mantuvo en funcionamiento hasta finales del IV.

En torno a la ciudad de Calagurris Iulia hay dos acueductos que daban servicio al enclave y a su territorium. Desde la sierra de La Hez proviene una conducción de entre 25 y 30 km iniciado en Ocón y atravesaba los términos municipales de Carbonera, Tudelilla, Bergasa, Arnedo y Calahorra ${ }^{13}$. La pendiente media es de $2.3 \%$ y una capacidad de transporte de $500 \mathrm{l} / \mathrm{s}^{14}$.
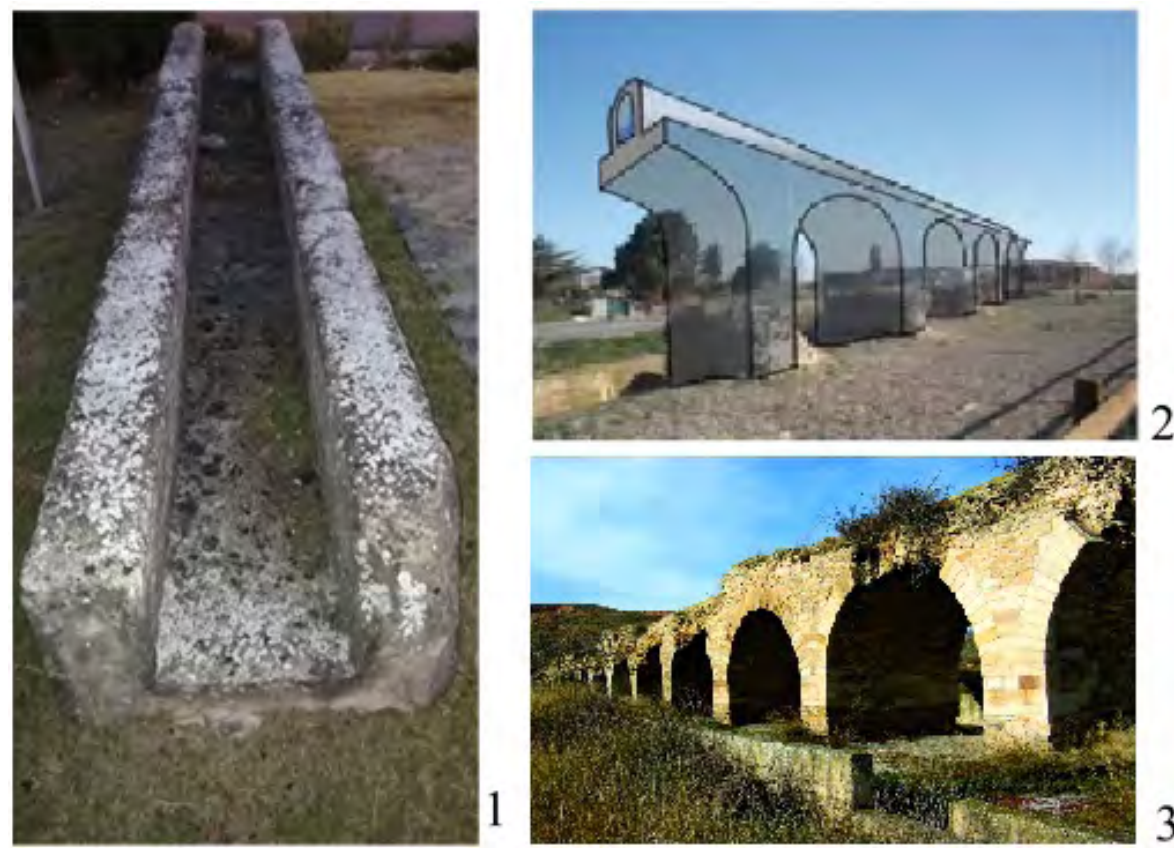

Figura 3. Acueductos de (1) Vareia, (2) Sierra de La Hez (reconstrucción del tramo arqueado) y (3) Tramo arqueado del de Alcanadre-Lodosa (tramo con rehabilitación) (Fuente: (1) elaboración propia, (2) Cinca, J. L. "Urbanismo y obras públicas... p. 102 y (3) Elaboración propia).

13. Se han localizado restos en 46 puntos con lo que se ha podido reconstruir su trazado (Cinca, J. L., "Urbanismo y obras públicas en el Alto Imperio", Castillo, Espinosa, Cinca, Luezas, Gómez y Barenas, "Edad Antigua", Cinca y González, Historia de Calahorra. Calahorra 2011, p. 101).

14. Pascual, M. P., "Abastecimiento de agua a Calagurris", Arqueología de Calahorra: miscelánea. Calahorra 1991, pp. 92. 
Debido a su longitud, se utilizaron tres tipos de modelos constructivos. La mayor parte de recorrido se realizó de manera soterrada con una caja de entre 55 y $58 \mathrm{~cm}$ de altura y entre 39 y $45 \mathrm{~cm}$ de anchura. Durante los primeros 10 $\mathrm{km}$, la conducción era una obra de opus caementicium sin paramento con un canal de opus incertum. Este diseño soportaba mejor las inclemencias climáticas de la sierra y la velocidad del agua ya que este es la parte del trazado con una mayor pendiente. En los siguientes $9 \mathrm{~km}$, la conducción corría paralela al río Majeco en dirección a la ciudad. Se introdujo una base de cantos rodados sobre la que se asentó la obra de cemento hidráulico y se levantaron muros de opus quadratum. El interior de la caja se revistió con opus signinum reforzado donde se ubicó el canal que soportaba una erosión menor al interior tramo. En los últimos $4 \mathrm{~km}$, los ingenieros se enfrentaron a la existencia de un cambio de cota debido a una vaguada ya dentro del término municipal calagurritano. Para poder salvarlo, se recurrió a la construcción de unas arquerías elevando el recorrido del acueducto de los que únicamente han sobrevivido en el cerro de Sorbán y en el topónimo del "Camino de los Cimentones". Los primeros tienen una distancia entre ellos de 5 metros y unos arcos cuya altura se ha estimado entre 2 y 3 metros $^{15}$. A partir de este punto se adentraba en la ciudad donde existiría un depósito regulador del que partía el sistema de distribución urbana $^{16}$.

Se trata de un acueducto cuya principal función era llevar agua de calidad a Calagurris lulia, aunque también debió dar servicio, mediante los oportunos permisos, a los enclaves rurales que se encontraban a lo largo de su recorrido y también a industrias como al taller de Gaius Valerius Verdullus, localizado en el alfar de "La Maja" (Pradejón-Calahorra), figlina donde se han descubierto los restos de la conducción que distribuía el agua en su interior ${ }^{17}$. Por lo tanto, era un acueducto de uso mixto del que debieron partir varias ramificaciones: regadío, industrial y, principalmente, de agua de boca. Se construyó entre el siglo I y el siglo Il y estuvo en funcionamiento hasta el IV ${ }^{18}$.

\subsection{Los sistemas de distribución urbana}

Dentro de los espacios urbanos, el agua que llegaba gracias a los acueductos era distribuida a lo largo de todo el enclave. Esta se utilizaba para el disfrute de

15. Los pilares están construidos con un alma de mortero y areniscas irregulares que se encuentra encofrado con un paramento exterior de sillarejo (Cinca, J. L., "Urbanismo y obras públicas... p. 102).

16. Que debía encontrarse en el entorno de la Planilla (Pascual, M. P. y García, P., "El abastecimiento de agua", Iguácel, Pavía, Cinca y Castillo, Así era la vida en una ciudad romana: Calagurris Iulia. Calahorra 2002, pp. 54-55).

17. Pascual, M. P. y García, P., "El abastecimiento de agua... p. 55.

18. Pascual, M. P. y García, P., "El abastecimiento de agua... pp. 94-95. 
sus habitantes en complejos termales, para actividades industriales, para que sus ciudadanos tuvieran acceso para sus fines privados o como parte de los rituales religiosos que se desarrollaban en el entorno.

La civitas de Vareia tenía un sistema de distribución modesta. Se trataba de una canalización subterránea que discurría por debajo del entramado viario. En los cruces de las calles, se instalaron fuentes públicas donde los vareyenses podían acudir para poder disponer de acceso al agua. Se han conservado dos: una que se tuvo una prolongada vida desde el altoimperio (Calle San Damián) y otra que se volvió a construyó de nuevo en el siglo V (Cruce de las calles San Cosme y Las Eras) ${ }^{19}$.

La primera fue realizada con sillares de arenisca asentados en seco con la entrada de agua en el oeste y la salida por el norte, aunque se encontraba en una cota superior para posibilitar que quedasen unos 472 litros de agua remansada. Para poder acceder a la fuente, se ejecutó una escalera en piedra que fue remodelada para que siguiera en servicio. La segunda se reconstruyó en el siglo $\mathrm{V}$ con múltiples materiales reutilizados con una entrada que se producía por el sur y una salida por el este. Estaba cubierta y la lámina de agua que se creaba pese a los problemas de filtraciones era accesible desde la misma calle ${ }^{20}$.

Calagurris lulia tuvo un sistema de canalización urbana más complejo que incluía cloacas para desaguar la aqua caduca que había sido utilizado en las diferentes actividades de la ciudad. En la zona del circo, se han descubierto varias canalizaciones que se han puesto en relación con este edificio público. Se trata de conducciones realizadas en opus caementicium y la mejor conservada se encontró en la calle Teatro 11. Servía para desaguar agua al exterior del gran edificio con un canal de agua de 0.40 metros de ancho, $1.40 \mathrm{~m}$ de alto y unas paredes de $26 \mathrm{~cm}$ de anchura. Estaba realizada en cemento de muy buena calidad con un revestimiento interno de mortero hidráulico y en interior se asentaba el canal que se cubría mediante una losa de arenisca ${ }^{21}$.

También se han encontrado canalizaciones en la zona de la calle San Andrés (números 5 y 31) y en la plaza homónima (número 68) que se han

19. Martínez, J. y Gallego, R., "Il. Vareia en el universo romano ... p. 165.

20. Las diferentes orientaciones de los caños de entrada y de salida de las fuentes hacen pensar a Jesús Martínez y Ramón Gallego en un sistema de distribución en sentido norte zigzagueantes entre las diferentes insulae posibilitando la existencia de una fuente por cada una de las manzanas (Martínez, J. y Gallego, R., "II. Vareia en el universo romano... pp. 166-167).

21. Las diferentes orientaciones de los caños de entrada y de salida de las fuentes hacen pensar a Jesús Martínez y Ramón Gallego en un sistema de distribución en sentido norte zigzagueantes entre las diferentes insulae posibilitando la existencia de una fuente por cada una de las manzanas (Luezas, R. A. y Andrés, G., "Calahorra. Obras hidráulicas... pp. 31-32). 
interpretado como conducciones de agua potable. Todas ellas tienen una técnica constructiva similar: está ejecutadas en opus camenticium con una anchura del specus entre los 70 y los $80 \mathrm{~cm}$. Se desconoce si servía para llevar agua potable a casas particulares o que si tenían alguna relación con el complejo termal que se excavó en sus inmediaciones ${ }^{22}$.

La ciudad contó con un sistema de cloacas de los que se han conservado cinco tramos a lo largo de toda la ciudad: en San Andrés 50 con un total de 41 metros de longitud, en el número 27 de la misma calle de $29 \mathrm{~m}^{23}$, en Planillo de San Andrés con dos tramos de 4 y 8 metros $^{24}$, en el conjunto de la Clínica ${ }^{25}$ y un quinto soterrado en el solar Tilos 5/Chavarría 17 dentro del complejo ARCCA. Los primeros comparten un método de construcción similar. Se ejecutaron mediante un encofrado de opus caementicium y una cubierta realizada con una bóveda de cañón y registros de ventilación. Todo este conjunto estaba soterrado y contaba con zonas de evacuación de aguas de la zona del conjunto termal. Los tramos de la Clínica y del ARCCA $^{26}$ presentan diferencias porque tanto la base como las paredes se realizaron en piedra y tenían losas de arenisca como cubiertas. Lo que sí comparten todo el sistema de cloacas es una cronología entre el siglo I y finales del III o inicios del IV, cuando finalizó su vida útil. Así mismo, todos ellos estaban en relación con los complejos termales "del Norte" y de "San Andrés". Conducciones privadas de evacuación de aguas negras también se han descubierto en la calle San Andrés, en sus números 31B y 14. Se ejecutaron en opus caementicium con una anchura del specus de unos $35 \mathrm{~cm}$ desconociéndose el tipo de cubierta ${ }^{27}$.

22. Un complejo termal que era de carácter público y es el de menores dimensiones de los investigados (Luezas, R. A. y Andrés, G., "Calahorra. Obras hidráulicas... pp. 32-33).

23. Cinca, J. L., "La red de saneamiento", Iguácel, Pavía, Cinca, y Castillo, Así era la vida en una ciudad romana: Calagurris Iulia. Calahorra 2002, pp. 64-66.

24. Ramos, M., "Seguimiento arqueológico de la urbanización del Planillo de San Andrés (Calahorra, La Rioja)", Kalakorikos 20 (2015), pp. 117-119.

25. Cinca, J. L. (2011) “Urbanismo y obras públicas... pp. 104-105.

26. Sistema de cloacas que cronológicamente es el más antiguo, de época augustea, y apenas estuvo en uso unos decenios (Gil, L. y Luezas, R.A., "Intervenciones arqueológicas en varios solares del entorno del centro comercial ARCCA de Calahorra (La Rioja) II". Kalakorikos 17 (2012), pp. 358-365).

27. Estos canales ponían en comunicación edificios particulares con la red general de cloacas mediante una fuerte pendiente (Luezas, R. A. y Andrés, G., "Calahorra. Obras hidráulicas... p. 33). 


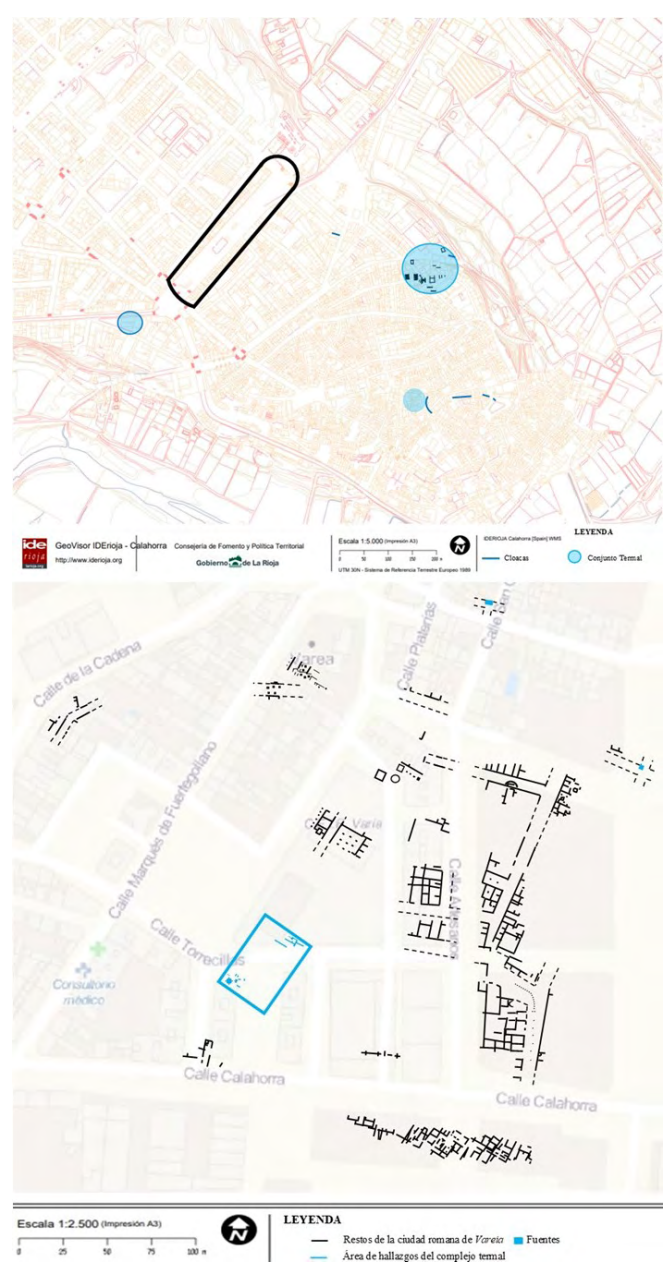

FiguRA 4. Sistemas de distribución urbana y otras infraestructuras hidráulicas de

(1) Vareia (Varea, Logroño) y (2) Calagurris Iulia (Calahorra) (Fuente: (1) Elaboración propia a partir de Martínez, J. y Gallego, R., "II. Vareia en el universo romano ... p. 194 y (2) elaboración propia a partir de Luezas, R. A., "Termas romanas en el Municipium ... pp. 185-192; Cinca, J. L., "Urbanismo y obras públicas... p. 94; Tudanca, J.M. y López de Calle, C., "Al otro lado del espejo. Vareia. 465 A.D.", Tejado (coord.), Vislumbrando la tardoantigüedad: una mirada desde la arqueología. Logroño, 2018, pp. 45-47).

En la parte alta del cerro donde se asentaba Graccurris, se descubrieron canalizaciones realizadas con un encofrado de mortero y cal todo ello recubierto 
con argamasa hidráulica. La conducción de mayor tamaño tiene $0.65 \mathrm{~m}$ de profundidad y $0.40 \mathrm{~m}$ de anchura y de ella partía otra de menor tamaña $(0.35$ x $0.30 \mathrm{~m}$ ). Todo ello formaba parte de un sistema que se debía repartir por toda la ciudad, aunque no se conocen más detalles salvo que darían servicio al gran edificio monumental de carácter religioso de época de Tiberio ${ }^{28}$, contemporánea a la construcción de la infraestructura de distribución de agua en la ciudad.

\section{Uso y disfrute: complejos termales y aprovechamiento industrial}

\subsection{Complejos termales}

Las termas de Varea han sido parcialmente excavadas. En primer lugar, se exhumaron $16 \mathrm{~m}^{2}$ de hipocausto con un muro de arenisca y ladrillos para la creación de la cámara de aire ${ }^{29}$. En segundo lugar, se encontraron dos piscinas y otro sistema de calefacción. El hipocausto tiene una extensión de $4 \mathrm{~m}^{2}$ con 14 pilae de $0.6 \mathrm{~m}$ de altura. La primera piscina fue un tepidarium que era calentado mediante el sistema de calefacción. Tenía una anchura de $9.2 \mathrm{~m}$, una profundidad de 1.14 y se estiman unos 14 metros de longitud. Se construyó con una separación de la zona de calor por ladrillos refractarios, un interior de opus camenticium y un enlucido de opus signinum que lo dotó de un color rojo característico. El sistema de acceso, al sureste, era una plataforma de ladriIlos que estaba decorado con un pavimento noble hoy perdido ${ }^{30}$. La segunda piscina es un frigidarium que se encontró convenientemente separada de la anterior, situada al este, mediante un doble muro de opus quadratum y de opus caementicium. Se investigó de manera parcial y solo se conocen su anchura de 3.8 metros, una longitud de $1.17 \mathrm{~m}$ y una profundidad de $1.19 \mathrm{~m}$. Como la anterior de realizó con cemento hidráulico y se realizó una moldura de sección

28. El sistema de distribución partía de un depósito que se tenía que ubicar en la parte alta del cerro y que se alimentaba de un hipotético acueducto que venía del Alhama-Linares (Martínez, J. M., "Excavaciones arqueológicas en las Eras de la Cárcel". Estrato. Revista riojana de Arqueología 5 (1993) p. 25).

29. Daba servicio al caldarium del complejo termal, aunque aún no se han encontrado restos del mismo (Cabada, J. J., Tirado, J. A., Heras, C. M., Andrés, S. "Estructuras termales en la ciudad romana de Vareia (Logroño, La Rioja)", Pérex, Termalismo antiguo. I Congreso peninsular. Arnedillo (La Rioja). 3-5 de Octubre de 1996. Madrid 1997, pp. 419-420; Heras, C. M. y Bastida, A. B., "Arquitectura romana de Varea: el conjunto termal". Estrato: revista riojana de arqueología 10 (1999), p. 61).

30. Martínez, J. y Gallego, R., "Il. Vareia en el universo romano... p. 168; Cabada, J. J., Tirado, J. A., Heras, C. M., Andrés, S. "Estructuras termales... p. 422; Heras, C. M. y Bastida, A. B., "Arquitectura romana de Varea... pp. 60-62, por su parte, alteran la orientación de la piscina y aportan unas medidas con una anchura de 2.25, una altura conservada de $0.84 \mathrm{~m}$ y longitud conservada de $6.7 \mathrm{~m}$. 
semicircular en la unión de las paredes con el suelo facilitando su limpieza. El acceso al interior de la piscina era posible gracias a dos escalones de 48 y 42 $\mathrm{cm}$ de altura ${ }^{31}$. Se trata de uno de los pocos edificios de carácter público que se han investigado en este enclave urbano ${ }^{32}$.

En Calagurris Iulia (Calahorra, La Rioja) se han intervenido dos complejos termales y hay testimonios de un tercero. Las denominadas como "Termas del Norte" son las de mayor extensión e indicios entorno a la confluencia de las caIles Eras, San Blas, Pastores y el yacimiento de la Clínica. Sin embargo, debido a que la mayor parte de las intervenciones han sido de urgencia o de escasa entidad, no es posible realizar una planta de complejo, aunque sí se puede describir algunas de sus estancias. La denominada "Pila de los Moros", destruida en los años 40, fue la piscina del frigidarium de $80 \mathrm{~m}^{2}$ y se dató a finales de la época de la dinastía Julio-Claudia. Tenía una base de cantos rodados sobre la que se ejecutó la piscina de mortero hidráulico en varias capas y un enlucido final ${ }^{33}$. En el solar de la antigua fábrica Torres, se descubrió otra piscina o cisterna de $60 \mathrm{~m}^{2}$ de $0.60 \mathrm{~m}$ de profundidad. En un inicio, se realizó con opus incertum de cantos rodados gruesos con mortero, pero se produjo una remodelación donde se mejoró la calidad de los muros en la segunda centuria. En el siglo III, la infraestructura quedó colmatada ${ }^{34}$.

Entre las calles Eras, San Blas y Pastores han aparecido estructuras de estas thermae en un área que abarca una superficie aproximada de $640 \mathrm{~m}^{235}$. Se ha propuesto que la piscina localizada en la calle Eras 35 fuera un tepidarium con muros de opus quadratum y un interior de opus caementicium que se ponía en comunicación con una estructura de combustión que apareció

31. Martínez, J. y Gallego, R., "II. Vareia en el universo romano... p. 168; Cabada, J. J., Tirado, J. A., Heras, C. M., Andrés, S. "Estructuras termales... p. 422; Heras, C. M. y Bastida, A. B., "Arquitectura romana de Varea... pp. 62-63. Estos últimos, como en el caso del tepidarium, estiman unas medidas para el frigidarium diferentes de $3.8 \mathrm{~m}$ de anchura y $1.7 \mathrm{~m}$ de longitud.

32. Se ha reconstruido de manera hipotética la planta de estas thermae en forma de " $L$ " en torno a un gran patio central o palestra, dos espacios independientes separados para hombres y mujeres que se unían en la zona donde se situaban las calderas. Este esquema era sencillo y funcional, similar al de las termas de Arcaya en Álava. Así mismo se explican las grandes dimensiones del complejo varayense debido a que daba servicio a la propia ciudad y a su entorno más inmediato (Martínez, J. y Gallego, R., "Il. Vareia en el universo romano... p. 169).

33. Luezas, R. A., "Termas romanas en el Municipium Calagurris lulia (Calahorra, La Rioja)", Fernández y García, Il Coloquio Internacional de Arqueología de Gijón. Termas romanas en el Occidente del Imperio (Gijón 1999). Gijón 2000, p. 185; Cinca, J. L., “Urbanismo y obras públicas... p. 98.

34. La remodelación se fecha en época antonina, momento de la tercera monumentalización de la ciudad (Tirado, J. A., El yacimiento del Solar Torres: niveles de ocupación prerromanos y romanos. Calahorra 2000, pp. 13-16).

35. Restos de cuatro piscinas (dos de ellas podían tratarse de cisternas), un praefurnium, un hipocausto, una pileta y una zona porticada (Luezas, R. A., "Arqueología urbana de Calahorra". Estrato. Revista riojana de arqueología 9 (1998), p. 24). 
también ese mismo número y en los números $16 / 18$ de la misma calle ${ }^{36}$. Las piscinas o posibles cisternas se construyeron de una manera muy similar con suelos de opus caementicium, muros de sillares y pavimentos con cuartos de bocel salvo la que se encontró en la calle San Blas que tenía muros de opus incertum y un revestimiento de opus incertum con una característica tonalidad roja ${ }^{37}$. Por último, hay que destacar una zona porticada entre los inmuebles de los números 23 y 25 de la calle San Blas donde se constató dos hiladas a base de sillares de arenisca de $80 \times 49 \times 40 \mathrm{~cm}$ que se pondrían en relación con un pilar localizado en el sondeo 3 del Solar Torres y con testimonio orales de tambores de columnas en la zona posiblemente de una zona de actividades al aire libre ${ }^{38}$.

La cronología del complejo se inició en el siglo I con la promoción jurídica de la ciudad en época de Augusto y posibles remodelaciones en época Flavia. Durante el siglo II, se realizó una amplia reforma en el conjunto y en la segunda mitad del siglo III, la construcción de la muralla bajoimperial fraccionó las termas en dos dejando la "Pila de los Moros" extramuros de la ciudad. El resto pudo continuar hasta el siglo IV ${ }^{39}$.

En la calle San Andrés (números 23, 25 y 29) se excavó parte de otro complejo termal con tres piscinas, un hipocausto y el desagüe. La más grande estaba realizada con opus caementicium y una superficie de $108 \mathrm{~m}^{2}$ (18 x $6 \mathrm{~m}$ ), otra de menor tamaño también ejecutada con argamasa y una tercera que albergó baldosas de mármol de 56×56×2 cm y una cornisa del mismo material fruto de un derrumbe. Se construyó sobre pilae de unos $6.5 \mathrm{~cm}^{40}$.

Por último, en el sur de la ciudad, durante la segunda mitad del siglo XX también se descubrieron varias piscinas, una de grandes dimensiones (120×60×2m), en la construcción de una fábrica de conservas. Se tiene constancia de estas mediante fotografías, testimonios orales y cultura material como ungüentarios y contenedores para perfumes o cosméticos de vidrio ${ }^{41}$.

36. Luezas, R. A., "Arqueología urbana... p. 25. y Luezas, R. A., "Termas romanas en el Municipium... pp. 186-187.

37. Luezas, R. A., "Arqueología urbana... p. 187.

38. Se trataría de un cierre del complejo termal (Luezas, R. A., "Arqueología urbana... p. 188.)

39. Luezas, R. A., "Arqueología urbana... p. 29.

40. Una de las piscinas fue remodelada en época bajoimperial con la instalación de un mosaico en la habitación (Iguácel, P., "El trazado urbano", Iguácel, Pavía, Cinca y Castillo, Así era la vida en una ciudad romana: Calagurris Iulia. Calahorra 2002, pp. 43-44; Cinca, J. L., “Urbanismo y obras públicas... pp. 98-99).

41. Fueron arrasadas por la construcción de fábricas y, posteriormente, de viviendas. Se trataría de las termas más grandes de la ciudad, coetáneas en el tiempo con la construcción del circo y cerca del paso de la calzada del Ebro (Luezas, R. A., "Termas romanas en el Municipium... p. 189). 

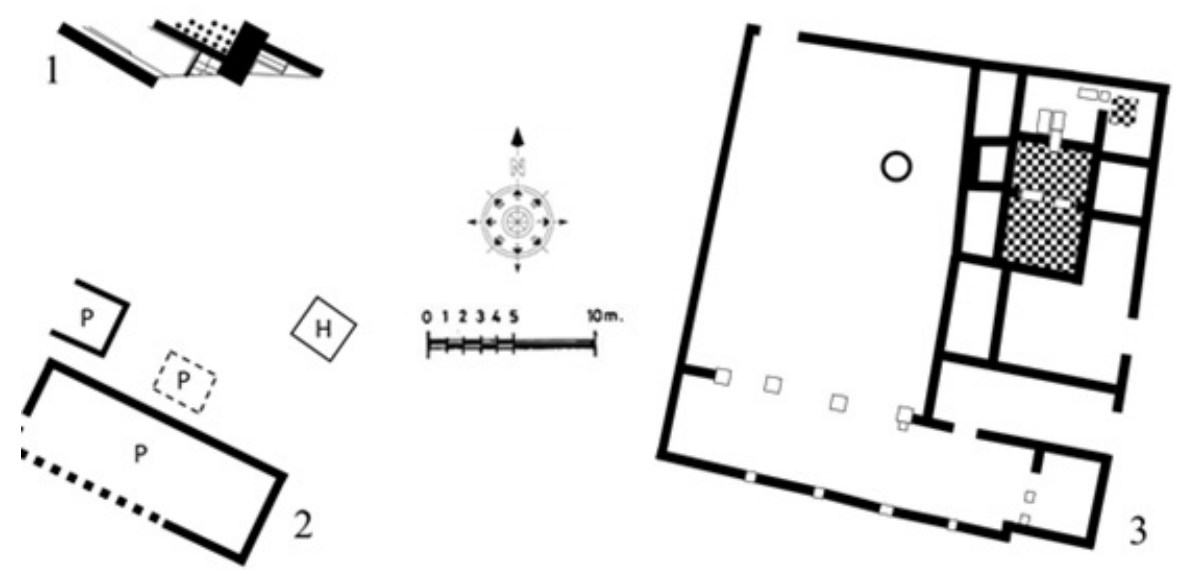

Figura 5. Complejos termales de (1) Vareia, (2) San Andrés (Calahorra, La Rioja) y (3) Andelos (Fuente: Elaboración propia a partir de (1) Heras, C. M. y Bastida, A. B., "Arquitectura romana... p. 69; (2) Cinca, J. L., "La presa romana... p. 97 y (3) Mezquíriz, M.A., Andelo. Ciudad romana..., pp. 56 y 71).

Para poder comprender los servicios que podían ofrecer estos complejos, hay que recurrir a un ejemplo que haya sido excavado en su totalidad. Las termas mejor conservadas y que se encuentran cerca del actual territorio riojano son las de Andelos (Mandigorría, Navarra). El complejo termal se construyó en la plataforma superior de la ciudad con un acceso desde el cardus más oriental. Constaba de un vestíbulo, las tres zonas a diferentes temperaturas (frigidarium, tepidarium y caldarium), los hipocaustos, el horno, las estancias auxiliares y una palestra para la realización de ejercicios. Todo el conjunto ocupaba una superficie de $950 \mathrm{~m}^{2}$. Tras la entrada estaba el apodyterium que tenía que contar con pequeños nichos donde se depositaba la ropa. Esta gran sala también constituía una especie de distribución para poder acceder a las diferentes salas climatizadas.

Todo el conjunto se ha conservado muy arrasado debido a las labores de expoliación y de las labores agrícolas. Las zonas templada y caliente se elevaban sobre un hipocausto constituido de un suelo elevado o suspensurae sobre pilae realizado con ladrillos cuadrados de $20 \mathrm{~cm}$ de lado y con una separación entre las pilae de $60 \mathrm{~cm}$. Así mismo el caldarium disponía de una piscina o alveus y una zona enlosada donde se ubicaba la sudatio. La entrada auxiliar se producía por el decumanus que corría al norte de la instalación termal. Servía para poder acceder a la zona donde se ubicaba el horno, el almacén de la leña y las calderas. Al oeste se hizo un patio donde se realizó un pozo para la captación de agua y una canalización ejecutaba con imbrices que pudo servir como un 
desagüe. Por último, hay que destacar la existencia de un pórtico de 14 × 6 metros al sur del complejo termal que ha sido interpretado como una palestra para la realización de actividades físicas ${ }^{42}$.

Estas instalaciones urbanas de carácter público tuvieron también su reflejo en otros complejos termales de carácter rural. Estos podían ser de acceso público como pueden ser los que estaban en las mansiones de las vías de comunicación o estar edificados en el interior de las propiedades privadas como son las explotaciones tipo villa. De estas hay varios ejemplos en territorio navarro que tendrían sus símiles en territorio riojano, tal y como se ha podido comprobar recientemente en el yacimiento de La Morlaca (Villamediana de Iregua $)^{43}$.

La villa de Liédena, excavada en la década de los 40 del siglo XX, llegó a contar con dos complejos termales. El bajoimperial es el mejor conservado y estaba situado al oeste contaba ocupaba una superficie de 65.72 $\mathrm{m}^{2}$ y contaba con un doble espacio absidado (apodyterium y tepidarium), el caldarium con una piscina pentagonal y el frigidarium al norte con una piscina rectangular de $3.30 \times 2.50 \mathrm{~m}$, restos de hipocausto y decoración con mosaicos ${ }^{44}$. El complejo oriental, por otro lado, estaban peor conservadas, pero eran una construcción de mayor calidad y corresponderían a la primera fase de la villa. Estas termas contaban con un apodyterium, un tepidarim rectangular, un caldarium con un ábside y un frigidarium con una piscina de $3 \times 1.80 \times 0.79 \mathrm{~m}^{45}$.

En la villa de Soto del Ramalete (Tudela, Navarra) el espacio termal se situaba al sur y contaron con, al menos, cinco habitaciones: el frigidarium con piscina, el tepidarium con hipocausto, el caldarium con hipocausto y piscina, el praefurnium para calentar el complejo y una palestra ${ }^{46}$. En la villa de Cabriana (Comunión, Álava) también se ha documentado una estructura termal localizada también en la zona sur en la que destaca un caldarium con dos piscinas gemelas, suntuosidad en la pavimentación marmórea, el hipocausto y el praefurnium con el almacén para la madera ${ }^{47}$. Más complicada es la función de las

42. Mezquíriz, M. A., Andelo. Ciudad romana. Pamplona 2009a, pp. 66-73.

43. Se han localizado los restos de dos piscinas que formaban parte del complejo termal (frigidarium y caldarium). Por ahora la información sobre estos restos únicamente se han publicado en prensa https://www.larioja.com/comarcas/pasado-romano-morlaca20191008193518-nt.html [consultado 24/11/2019].

44. Taracena, B., "Excavaciones en Navarra. La villa romana de Liédena. Capítulo II". Príncipe de Viana 37 (1950), pp. 27-28; Mezquíriz, M. A., "Las "villae" tardorromanas del Valle del Ebro". Trabajos de arqueología navarra 21 (2009b), p. 225.

45. Taracena, B., "Excavaciones en Navarra... pp. 29-30.

46. Se fecha en los siglos bajoimperiales (Mezquíriz, M. A., "Las 'villae' tardorromanas... p. 229).

47. Ortiz de Urbina, C. y Pérez, E., "El inicio de la arqueología en Álava: D. Lorenzo de Prestamero y Cabriana". Veleia 1 (1990), pp. 108-110 y pp. 114-115. 
estructuras hidráulicas de la villa de Los Ladrillos (Tirgo, La Rioja). Se trata de un arroyo acondicionado, un sistema de almacenamiento mediante un aljibe y restos de otras infraestructuras ligadas al agua, pero con una función aún desconocida $^{48}$.
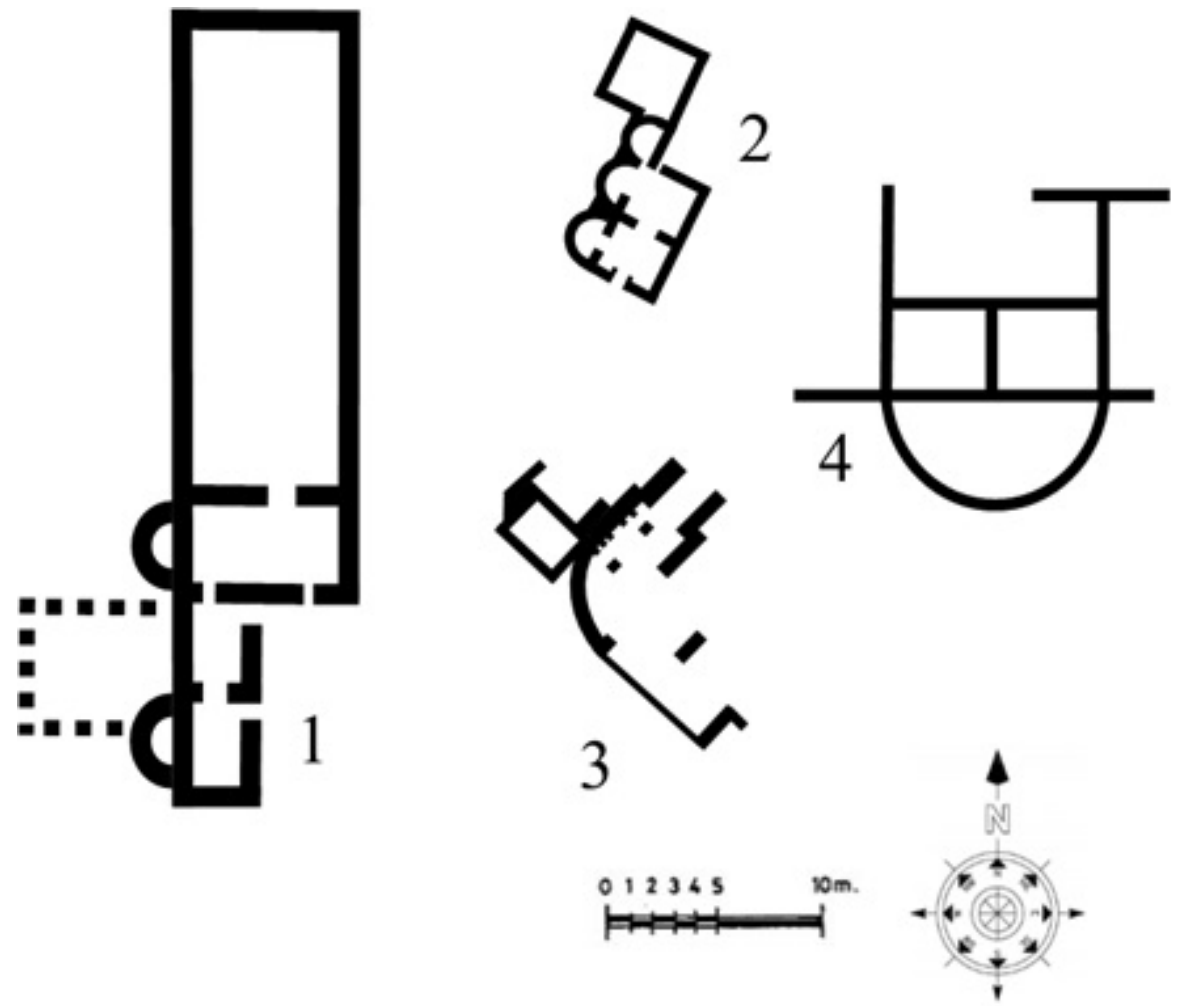

Figura 6. Complejos termales rurales de (1) Soto del Ramalete (Tudela, Navarra); (2) Liédena (termas occidentales); (3) Liédena (termas orientales) y (4) Cabriana (Fuente: Elaboración propia a partir de (1) Mezquíriz, M.A., "Las "villae" tardorromanas... p. 226; (2 y 3) Taracena, B., "Excavaciones en Navarra... Lam. III y (4) Ortiz de Urbina, C. y Pérez, E., "El inicio de la arqueología... p. 109).

48. Se encontraron en las unidades 66 y 67 . En la parte alta del yacimiento se encontró una posible piscina, en el interior de la villa una piscina que en época bajoimperial es remodelada para convertirse en un aljibe y el cauce del antiguo arroyo del Molinar que fue acondicionado como una canalización (Porres, F., "Tirgo. El yacimiento romano de 'Los Ladrillos'. Estudio de los materiales". Estrato 12 (2000), pp. 49-53). 
Aprovechando la presencia de aguas termales en el término municipal de Fitero, se aprovechaba su poder sanador de estos manantiales, hoy en día aún en uso. Según Lletget durante unas obras llevadas a cabo en 1861, se exhumaron los restos constructivos de un edificio rectangular con tres ábsides y la presencia de 14 piscinas circulares alineadas en dos hiladas de siete ${ }^{49}$. El agua sale a $52^{\circ}$ según los propietarios del actual balneario y $46^{\circ}$ según un informe geológico realizado en 1982 por lo que no era necesario ningún sistema de calefacción $\operatorname{artificial}^{50}$.

Actualmente se conserva una de las piscinas circulares y el castellum aquae. La piscina tiene un diámetro de $2.08 \mathrm{~m}$ y una profundidad superior a 1 metro con dos bancos corridos concéntricos a diferentes alturas. El castellum o arqueta de captación y distribución de agua se ejecutó con grandes sillares y una cornisa en su parte superior. Esta se interrumpe en la parte central donde quedó un siIlar rectangular y saliente donde pudo haber una inscripción. La infraestructura tiene planta cuadrangular de $5.52 \mathrm{~m}$ de lado y una altura máxima de $1.85 \mathrm{~m}^{51}$. Se presupone una fecha de construcción entre el siglo I o comienzos del II52.

En 1930, Saturnino Mozota describió la existencia de una galería de conducción de agua de $65.44 \mathrm{~m}$ de largo, $1.75 \mathrm{~m}$ de alto y $0.78 \mathrm{~m}$ de ancho, aunque no podía especificar si se trataba de una obra de época romana ${ }^{53}$. En unas llevadas a cabo en 1982, justo en la ladera situada encima de la arqueta, se encontraron restos de estancias de $4.41 \times 3 \mathrm{~m}$ y una altura máxima conservada de $2.84 \mathrm{~m}$ con parte de la misma excavada en la roca natural alisada. En las inmediaciones también se descubrieron restos de más habitaciones. Por su situación junto al castellum, se piensa que pudieron corresponder a una serie de cámaras para poder tomar baños de vapor ${ }^{54}$.

\subsection{Aprovechamiento industrial}

El embalse de la Degollada, en el territorium de Calagurris lulia, tenía una función clara: regar la zona noreste de la centuriación calagurritana. El

49. Pérex, M. J. y Martín, C., "Aguas termales y mineromedicinales en el valle del Ebro. Su incidencia en el poblamiento en época romana", Castillo y Iguácel, Studia Histórica in Honorem Prof. Urbano Espinosa Ruiz. Logroño 2018, p. 188.

50. Mezquíriz, M. A., "Las termas romanas de Fitero". Trabajos de arqueología Navarra 17 (2004b), pp. 274 y 278.

51. Las gradas están realizadas con sillares tallados a modo de dovelas y conserva el canal tallado en la piedra donde se incrustaría el tubo de plomo por donde sr vertía el agua caliente. Mezquíriz, M. A., "Las termas romanas... p. 278.

52. Pérex, M. J. y Martín, C., "Aguas termales y mineromedicinales... pp. 188-189.

53. Se ha puesto en relación con el resto de la instalación de cronología romana pero aún no se ha podido comprobar de manera fehaciente su adscripción romana (Mezquíriz, M. A., "Las termas romanas... p. 275).

54. Pérex, M. J. y Martín, C., "Aguas termales y mineromedicinales... p. 189. 
acueducto de Alcanadre-Lodosa parece que tuvo una finalidad similar una vez que se ha descartado que abasteciera a la ciudad debido a la diferencia de cotas entre la margen riojana y la situación de la ciudad que lo hacía inviable. El origen de esta conducción se producía en la confluencia de los cursos del Odrón y el Linares mediante un azud de derivación en Lazagurría (Navarra) para luego seguir las curvas de nivel por el barranco Salado, pasando por la carretera de Lodosa a Mendavia para girar y atravesar el Ebro mediante una arquería de 108 arcos y 624 metros de longitud para seguir por la ribera riojana hasta terminar en la zona norte del término municipal de Calahorra ${ }^{55}$. La obra se fecha en el siglo II. Mezquíriz piensa que el tramo elevado sobre el Ebro pudo servir de paso debido a la anchura de la obra. El canal también disponía de un sistema de compuertas para favorecer la correcta conducción de agua ${ }^{56}$.

Los complejos alfareros necesitaban una gran cantidad de agua para garantizar su funcionamiento. Uno de los lugares que más indicios ha dado de esta actividad industrial es el foco del Najerilla, entre la antigua Tritium Magallum y el área emilianense de época bajoimperial. En las excavaciones llevadas a cabo en mayo de 2001 en la Finca de Arcos, se descubrieron una serie de estructuras en cuatro sondeos. Los resultados del sondeo 1 fueron interpretados, pese a la parcialidad de la intervención, como una zona de cocina y almacenamiento de una vivienda con una conducción realizada con imbrices. El sondeo 2 deparó un canal realizado por bloques de piedras ensamblados con una anchura de $36 \mathrm{~cm}$ y una altura de $20 \mathrm{~cm}$. Se teorizó con que fuera una acequia ${ }^{57}$.

Entre los años 2007 y 2008, se excavaron tres áreas en el área exterior de la ermita de $\mathrm{N}^{\mathrm{a}} \mathrm{S}^{\mathrm{a}}$ de Arcos, lugar donde se iba a efectuar obras de mejora y consolidación. Se descubrió un área suburbana que se dedicaba a actividades industriales de tipo alfarero. En el sondeo 1 se exhumó una estancia

55. Mezquíriz, M. A., "El acueducto de Alcanadre-Lodosa". Trabajos de arqueología Navarra 17 (2004a), pp. 257-258.

56. El canal discurría a cielo abierto con una anchura variable entre los 2 y los 2.5 metros entre paredes de sillería irregular de entre 1 y 2 metros de altura y una pendiente de entre el $1 \%$ y el 1 por mil. Se le calcula un caudal de $2.88 \mathrm{~m}^{3} / \mathrm{s}$ con tramos reforzados con mortero hidráulico en las curvas para contrarrestar el empuje de agua. El tramo arqueado es el más espectacular de toda la obra de casi $30 \mathrm{~km}$ con arcos de $4.70 \mathrm{~m}$ de luz, $1.10 \mathrm{~m}$ de ancho en los pilares, 3 metros de distancia entre los paramentos y un specus de $1.45 \mathrm{~m}$ de ancho. El método de construcción es un paramento de sillares y sillarejos que sirve de encofrado a un alma de opus caementicium aglomerado con mortero (Mezquíriz, M. A., "El acueducto de Alcanadre-Lodosa... pp. 255-260).

57. La funcionalidad de los restos encontrados en el sondeo 2 no estaba claro: acequia de riego o transporte de agua para la industria alfarera, esta última la más plausible (Alonso de Medina, I., "Sondeos realizados en la finca urbana de Arcos (Tricio)". Estrato 13 (2001), pp. 57-60). 
rectangular con una canalización de piedra ejecutada de una manera muy similar al que se descubrió en el año 2001 en una finca cercana y un desagüe. En el área 3 se hallaron las estancias productivas de un alfar con la presencia de varios moldes, dos piletas y canalización por lo que se trataba de una sala para el trasvase de líquidos. La canalización era de piedra y tenía una longitud conservada de $64 \mathrm{~cm}, 50 \mathrm{~cm}$ de anchura y $35 \mathrm{~cm}$ de altura y vertía su contenido en la pileta número 1. Esta, a su vez, estaba orientada hacia la parte central de la estancia al igual que la pileta número $2^{58}$. Gracias a todas estas excavaciones se sabe que en los entornos alfareros de carácter industrial de la antigua Tritium Magallum, se tuvo que desarrollar una gran red de acequias que distribuían el agua hacia los diferentes espacios artesanales. Tras su uso, el exceso de agua era desaguado hacia el exterior de las estancias por donde eran conducidas por el entramado viario para propiciar su eliminación.

El alfar de La Maja, en el territorio jurídicamente adscrito a la civitas calagurritana, se produjo cerámica de paredes finas decoradas a molde firmadas por Gaius Valerius Verdullus, de vidrio soplado, de almacenaje, de transporte y material de construcción. Este complejo estaba bien situado porque tenía acceso a la materia prima necesaria en su entorno más inmediato, la vía De Italia in Hispanias pasaba al norte y el acceso al agua quedado garantizado gracias al acueducto de la sierra La Hez, aunque se desconoce cómo se producía la conexión ${ }^{59}$. Sí se ha podido descubrir varias pileras de decantación y el sistema de canalización de agua realizada con imbrices ${ }^{60}$.

El uso del agua como fuerza de tracción también se utilizó para poder accionar molinos hidráulicos que se han encontrado en las cuencas del Leza y del Jubera en contextos bajoimperiales. Una muela inferior arrancada de su posición original se encontró en un establecimiento tipo villa junto al curso del Leza mientras que, a la altura de Santa Engracia del Jubera, junto al curso homónimo, se halló una muela superior en el despoblado de Venturriel en un contexto también tardorromano ${ }^{61}$.

58. Alonso, C., Nuestra Señora de Arcos (Tricio, La Rioja) de basílica a ermita a la luz de la arqueología. Logroño 2015, pp. 47-55 y pp. 76-81.

59. Aunque si hay indicios del acueducto en las inmediaciones y conducciones internas (Luezas, R. A., "Manifestaciones artísticas en Calagurris Iulia", Castillo, Espinosa, Cinca, Luezas, Gómez y Barenas, "Edad Antigua", Cinca y González, Historia de Calahorra. Calahorra 2011, pp. 124-127).

60. Se realizó a base de cerámica de construcción, en concreto, a base de imbrices (González, A., "El alfar de La Maja adquiere dimensiones insospechadas. Campaña de julio de 1995". Estrato 7 (1996), pp. 49-64 y (1997), pp. 27-28).

61. Ambas son muelas que fueron accionaron por tracción hidráulica y formaban parte de, al menos, dos molinos (Pascual, P. y García, P., "Canteras y tecnología molinar... pp. 244-245). 


\section{Dimensión social: ingeniería, derecho y religión}

\subsection{Los valles y las vías}

El entramado viario de época romana en el Ebro Medio tuvo un gran desarroIlo y los ingenieros aprovecharon los valles fluviales para poder ejecutar las diferentes calzadas, la influencia de estos conjuntos naturales determinó el trazado de las calzadas. La más importante fue la recogida en el Itinerario de Antonino bajo la nomenclatura 1/32 De Italia in Hispania/Ab Asturica Terracone Partía de Italia, entraba en la Península Ibérica por el actual levante catalán y, posteriormente, viraba hacia el oeste utilizando la Depresión del Ebro para poder finalizar en el Noroeste. En la zona de estudio propuesta, esta arteria tenía una mansio en las principales civitates de la margen derecha del Ebro: Cascastum (Cascante, Navarra), Graccurris (Alfaro, La Rioja), Calagurris lulia (Calahorra, La Rioja), Vareia (Varea, Logroño, La Rioja), Tritium Magallum (Tricio, La Rioja) y Libia (Herramelluri, La Rioja). El trazado de la vía continuaba de manera paralela al curso del Ebro hasta Varea donde se separaba rumbo suroeste para poder llegar al entorno tritiense, importante foco alfarero ${ }^{62}$. Hay que recordar que, según Plinio, Vareia era el límite de la navegabilidad del Ebro así que este hecho podría explicar que esta arteria principal se separase del curso principal internándose hacia Tricio ${ }^{63}$.

Desde Logroño, una calzada de carácter secundario continuaba siguiendo el cauce del Ebro hasta el Paso de las Conchas de Haro y los Montes Obarenses $^{64}$. En cada uno de los valles trasversales norte-sur que nacen en el Sistema Ibérico y desembocan en el Ebro, se trazaron vías de carácter secundario que enlazaban el valle con la meseta: la vía del Alhama que unía Graccurris con Numancia, la del Cidacos entre Calagurris Iulia y Numancia, la del Leza y la del Jubera que también tenía como final la ciudad numantina, la del Iregua entre Vareia y la misma ciudad, la del Najerilla entre Tritium Magallum y Nova Augusta-Clunia y la del Oja-Tirón que dinamizaba este valle ${ }^{65}$. Un epígrafe a los Lares Viales encontrada en Cervera de Río Alhama es el único testimonio

62. De Italia in Hispanias: Itin. Ant. 387.4-395.4. Item ab Asturica Terracone: Itin. Ant. 448.2-452.5.

63. El cambio de trazado entre Vareia y Tritium Magallum desviándose del cauce del Ebro puede deberse a que la vía servía como apoyo a la navegabilidad del río (Castillo, M. J., "Ríos y calzadas en el valle del Ebro... pp. 47-72).

64. Articulaba el entorno rural hasta los Obarenses y la desembocadura de los tributarios del Ebro como Oja-Tirón o el Najerila (Santos, J. y Calonge, A., "El entramado viario romano en el norte de La Rioja. Sobre la calzada paralela al Ebro (Logroño-Cihuri)", Castillo y Iguácel, Studia Historica in Honoren Prof. Urbano Espinosa Ruiz. Logroño 2018, pp. 205-232).

65. Para más información sobre las vías trasversales entre el valle del Ebro y la Meseta a través del Sistema Ibérico: Ariño, E. y Magallón, M. Á., "Problemas de trazado de las vías romanas en la provincia de La Rioja". Zephyrus 44-45 (1991-1992), pp. 447-450. 
epigráfico vinculado a una de las calzadas de carácter secundario, en este caso, la del Alhama ${ }^{66}$.

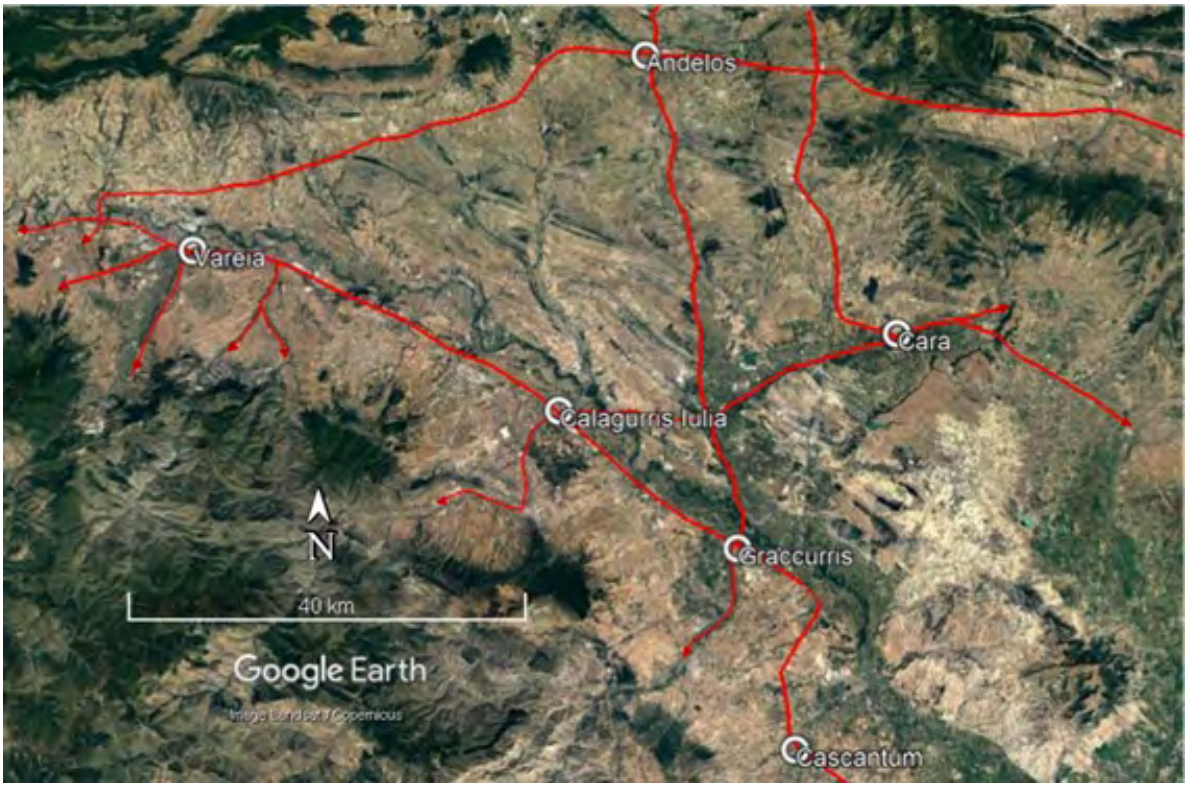

Figura 7. Entramado viario del Ebro Medio (Fuente: Elaboración propial Google Earth).

\subsection{La jurisprudencia del agua}

En el actual territorio riojano, no se han encontrado testimonios jurídicos de época romana por lo que se desconocen las leyes municipales de las civitates u otros documentos que regían algunas de las infraestructuras hidráulicas de la región. Por ello, hay que recurrir a ejemplos exteriores al área de estudio propuesta.

En Agón (Aragón), apareció un bronce jurídico con una inscripción que proporciona información sobre el funcionamiento de una comunidad de regantes fechada en época de Adriano (117-138). Es conocido como la Lex Rivi Hiberiensis, seguramente en referencia a que el canal principal podría tener su toma en el Ebro. Sobre la administración del canal y sus aguas, señala los turnos de riego, el periodo de limpieza de la infraestructura, las contribuciones que de-

66. CIL II 2987; ILER 584; ERRioja 3. 
bían hacer los regantes para el mantenimiento y reparación de la conducción principal, las sanciones derivadas del incumplimiento del ius aqua y cómo se articulaban los ramales secundarios de carácter privado. ${ }^{67}$

Se trata de un documento de excepcional importancia para poder conocer cómo se articulaba el poblamiento rural en torno a los distritos rurales o pagi y también sobre grandes infraestructuras hidráulicas destinados al aprovechamiento agrícola, aunque se desconoce el canal que regulaba. No es descabellado plantear que el acueducto de Alcanadre-Lodosa, de unos $30 \mathrm{~km}$ de longitud, pudiera disponer de también de un reglamento jurídico similar ${ }^{68}$.

En la rúbrica 82 de la Lex Irnitana (El Saucejo, Sevilla) se habla de cómo los dunvirii tenían la potestad de poder construir o reformar diferentes obras de carácter público siempre y cuando estuviera en los límites del municipio y no afectase a los particulares. En ese compendio de infraestructura, se mencionan los cauces, los canales y las cloacas. En el Digesto, Ulpiano recoge cómo había que proteger y mantener en condiciones óptimas el curso y las orillas de los ríos. Para ello se prohibía que se construyera o se permitiese la existencia de obstáculos que impidiera la actividad o el atraque en las orillas ${ }^{69}$, se protegía la navegación fluvial ${ }^{70}$ y cómo las márgenes debían mantener o, en su caso, repararse $^{71}$. Estas labores se recogían también en la legislación urbana mediante el pago de impuestos (Lex Ursonensis, cap. 77 y 98) o del trabajo de ciudadanos y foráneos que viviera en la ciudad y que contasen con una edad entre los 15 y los 60 años (Lex Irnitana, rúbrica 83).

\subsection{La dimensión religiosa}

En Graccurris se han descubierto varios edificios religiosos que usaban el agua como medio ritual o que tenían como objeto de culto divinidades acuáticas. En época de Tiberio, se produjo una renovación urbanística de la

67. Es un documento muy interesante que habla sobre el funcionamiento, las atribuciones de los magistrados y la dependencia con respecto a ciudades de los pagi. La participación de los magistri pagi y de recursos de los publicani indican que el sistema se basaba en una financiación de carácter público, al menos en lo referente al o los canales principales y que, para aprovechar el agua que los recorría, se tenía que pagar una cuota. Sin embargo, no se conservan las disposiciones por las que se regulaba el aprovechamiento del agua ni los turnos del regadío. Beltrán, F. y Willi, A., "El regadío en la Hispania Romana. Estado de la cuestión". Cuadernos de prehistoria y arqueología de la Universidad de Granada 21 (2011), p. 21 y pp. 28-29.

68. Conllevaría la existencia de múltiples canales que daban servicio a las vegas del Ebro y sus tributarios (Beltrán, F. y Willi, A., "El regadío en la Hispania Romana... p. 31).

69. Digesto XLII. 12[11].1.

70. Digesto XLIII.14[13].1.

71. Digesto XLIII.15[14].1. 
ciudad que conllevó una monumentalización de la ciudad. Especialmente interesante es el edificio monumental, que se levantó en el centro de la ciudad, al que se le han atribuido funciones religiosas. Tenía planta rectangular y una orientación norte-sur. En su parte septentrional tiene tres estructuras rectangulares a las que les sigue un espacio porticado con columnas toscanas $y$, posteriormente, una gran piscina. El acceso se efectuaba por el oeste. Esta tiene 36.5 metros de anchura, una profundidad de $2.5 \mathrm{~m}$ y una longitud de $35 \mathrm{~m}$ aunque aún no se ha terminado de excavar ${ }^{72}$. Se construyó en el siglo I con ampliaciones en la siguiente centuria y continuó en uso hasta finales del $\mathrm{III}^{73}$.
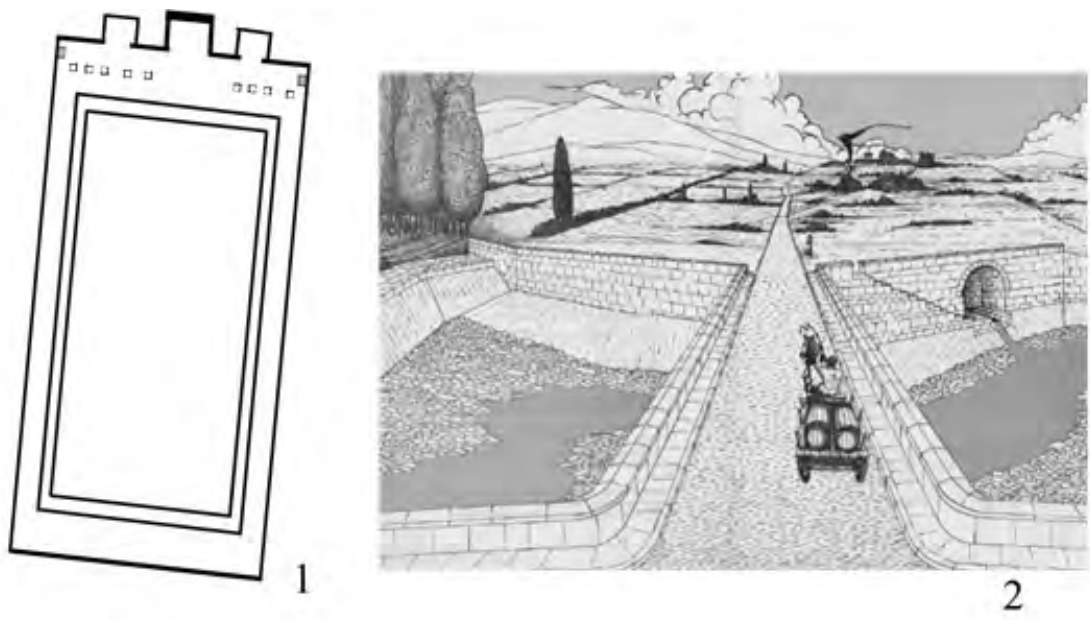

$50 \mathrm{~m}$

Figura 8. Complejos religiosos de Graccurris. (1) Gran edificio de época altoimperial y (2) restitución del Complejo Monumental de "El Burgo"74.

72. Conocemos una anchura de $36.5 \mathrm{~m}$, una profundidad de $2.5 \mathrm{~m}$ y una longitud que supera los 35 m. Véase: Martínez, J. M. y Del Fresno, P., Evolución del poblamiento altomedieval de las Eras de San Martín. Síntesis de los Resultados de las campañas 2000 a 2005. Alfaro, Graccurris. Equipo de investigación arqueológica 2006, p. 11. Recuperado de internet (http://www.graccurris.info/gr/index.php/es/informes-2006) [consultado 09/12/2018]; Martínez, J. M. y Jordán, C., "Una tésera celtibérica y algunas inscripciones sobre instrumentum procedentes de Graccurris (Alfaro, La Rioja)". Paleohispanica 16 (2016), p. 263.

73. Gracias a la excavación de casi $75 \mathrm{~m}^{2}$ de la piscina hasta su fondo, se ha constatado una función religiosa para la misma entre los siglos II y III (Martínez, J. M. y Jordán, C., "Una tésera celtibérica..., pp. 263-264).

74. Fuente: (1) Elaboración propia a partir de Martínez, J. M. y Jordán, C., "Una tésera celtibérica... p. 262 y (2) Ariño, E., Hernández, J.A., Martínez, J. N. y Nuñez, J., "Graccurris: conjuntos monumentales... pp. 8-9. 
En los conjuntos monumentales de la periferia de la ciudad alfareña, de los que ya se han descrito las presas, se construyeron también ninfeos. La originalidad de estos radica en que fueron planificados y ejecutados de manera unitaria donde convivía varias infraestructuras y realidades: hidráulicos, viarios y religiosos. En el entorno de Graccurris se llegaron a construir dos de estas infraestructuras.

El conjunto de "El Sotillo" se edificó a finales del periodo republicano o al inicio del Principado pero sucumbió en algún momento entre finales del siglo I y principios del II. Llegó a contar un pequeño templo y un lacus que debió estar vinculado con una fuente sagrada. La reconstrucción de su planta es problemática, aunque se ha propuesto que se trate de un edificio in antis con pilastras con decoración mediante acanaladuras, fustes pertenecientes al orden corintio y un tejado a dos aguas ${ }^{75}$. El estanque estaría situado en el sector suroccidental de la pantalla, donde se descubrió una cimentación basada en cantos rodados, arcilla y algún sillar. Junto a ella se descubrieron los restos pétreos del lacus: los elementos que servían de perímetro de la lámina de agua, los refuerzos de las esquinas y su sistema de desagüe. Este consistía en una tubería de plomo protegido con sillares trabajados a tal efecto ${ }^{76}$.

El conjunto de "El Burgo" entró en servicio, como muy tarde, en los primeros decenios del siglo II. El ninfeo se situaba en una prolongación del estribo del puente, en la pantalla aguas abajo. Mediante una escalera realizada en piedra, se accedía directamente desde la calzada a la fuente que se realizó en el interior de una exedra cubierta por una bóveda de cañón por donde circulaba un canal de agua. Esta salía de un muro situado en el interior de la cámara que tenía cuatro canales situados a tres niveles diferentes lo que posibilitaba que el flujo de agua fuera constante independientemente de los cambios del nivel del líquido. Tras esta pantalla, se construyó una arqueta de toma ejecutada mediante dos hiladas de sillares y una bóveda de ladrilla. La pared del fondo se realizó con cantos rodados para lograr una filtración del caudal subterráneo y permitía su decantación mediante un pequeño estanque ${ }^{77}$.

Hay que pensar en la existencia de epígrafes dedicados a las Ninfas en cada una de las obras de las que no hay constancia. En La Rioja, sin embargo, no se

75. El edificio religioso, del que apenas se conservan aquellos elementos que no pudieron ser reutilizados cuando toda la obra arruinada sirvió de cantera: molduras, capiteles o fustes corintios. (Hernández, J. A., Ariño, E., Martínez, J. M. y Nuñez, J., "La presa y el ninfeo del Sotillo... pp. 245-250).

76. Se presupone que tendría una cubierta de madera y se propone un aspecto semejante al ninfeo de Formia, junto a la Vía Appia (Hernández, J. A., Ariño, E., Martínez, J. M. y Nuñez, J., "La presa y el ninfeo del Sotillo... pp. 250-253 y pp. 258-260).

77. Los investigadores hablan de la existencia de una fuente en la pared norte de la exedra de la que sólo han sobrevivido una hilada de sillares (Hernández, J. A., Ariño, E., Martínez, J. M. y Nuñez, J., "Contribución al estudio de las presas... pp. 229-233 y pp. 234-236). 
han conservado inscripciones por lo que, de nuevo, hay que recurrir a las comunidades vecinas de Navarra y País Vasco. Dos son los testimonios epigráficos en territorio foral que rinden tributo a las Ninfas: el ejemplar de Barbarín y el del Monasterio de Leyre. El primero es una sencilla ara realizada por orden de la liberta Sempronia Flava en el entorno de la antigua Curnonium (Los Arcos). Se trata de una arenisca tallada con corona y una prominente base ${ }^{78}$. La del Monasterio de Leyre es una pieza muy interesante ${ }^{79}$ por varios motivos: porque el origen del dedicante, por su profesión y por el lugar de su hallazgo. Se trata de un ara votiva de arenisca, de forma rectangular y que se reutilizó como sillar para la construcción del cenobio. Fue mandada hacer por Quinto Licinio Fusco de Vareia (Varea, Logroño) siendo el primer y único testimonio epigráfico de este toponímico que se conserva.

Este vareyense era un aquilegus, es decir, alguien que se dedicaba a encontrar y poner en explotación corrientes de agua. En la península ibérica únicamente se dispone de otra mención a esta profesión en un epígrafe descubierto en Boñar (Provincia de León, Castilla y León) ${ }^{80}$. Mezquíriz relaciona el ara de Leyre con la Fuente de las Vírgenes cuya arqueta de recogida de agua puede ser de origen romano, pudo formar parte de un ninfeo, hoy desaparecido, que luego se cristianizó y lo pone también en relación con el entramado viario de la zona $^{81}$. Así mismo, ha sido relacionado con los baños de Tiermas, hoy bajo las aguas del embalse de Yesa ${ }^{82}$.

En Álava, también se han descubierto varias piezas dedicadas a las Ninfas y divinidades acuáticas. En Cabriana aparecieron dos aras a las ninfas y otra a Uvarna $^{83}$, identificada como una posible diosa vinculada con la hidrografía de la zona según Elorza que sigue las tesis de Baraibar ${ }^{84}$. Los testimonios a las Nin-

78. S(empronia)·Flava/Nym/phis/ v(otum)·s(olvit)·l(ibens)·m(erito) (Armendáriz, J. y Velaza, J., "Nueva ara romana de Barbarin (Navarra)". Sylloge Epigraphica Barcinonensis 4 (2002), pp. 47-50).

79. Quintus/Licinius/Fuscus·aquile/gus·varaien/sis·Nimpis/vivens·m(erito)/v(otum)·s(olvit) (Armendáriz, J. y Velaza, J., "Nueva ara romana de Barbarin (Navarra)". Sylloge Epigraphica Barcinonensis 4 (2002), pp. 157-166).

80. CIL II 2694 (p 709); CIL II 5726; CIL VI, 152 (p 3004); IRPLe 60; HEp 1, 1989, 385; HEp 9, 1999, 403; AE 1999, 822; AE 1999, 919.

81. Mezquíriz, M. A. y Unzu, M., "Presencia de un aquilegus en Leire. Posible sustrato romano". Trabajos de arqueología Navarra 15 (2001), pp. 157-166.

82. Espinosa, U. y López, R., "Agua y cultura antigua en el alto-medio Ebro", Pérez (ed.), Termalismo antiguo Actas del I Congreso Penínsular. Arnedillo (La Rioja). 3-5 de Octubre de 1996. Madrid 1997, p. 262.

83. Uvarnae/pro·salute/Estiteri·f/abri [s(olvit).l(ibens)·m(erito)] (Elorza, J. C., "Ensayo topográfico de epigrafía romana alavesa". Estudios de arqueología alavesa 2 (1967), pp. 134-135).

84. También se han relacionado a los cultos a las Matres Useae, con epígrafes en Canales de la Sierra (La Rioja) y Laguardia (Álava); y a Caldus Uledicus, con un ara encontrada en la localidad riojana de El Rasillo de Cameros, con el agua, en este último caso, con una divini- 
fas se encontraron en el interior de una presa (dedicada también a los Lugares) ${ }^{85}$ y la segunda muy deteriorada ${ }^{86}$. Se propone que podía estar en proceso de talla por lo que Cabriana podría ser un lugar de culto a estas divinidades. En Araya, en el nacimiento del río Ciraunza y muy posiblemente vinculada a este curso, se halló una tercera pieza dedicada a las Ninfas ${ }^{87}$. Más dudosa es la inscripción a estas divinidades del municipio riojano de Tricio encontrada en el siglo XIX en la plaza de San Miguel que hoy se encuentra desaparecida ${ }^{88}$.

\section{Conclusiones}

Las diferentes infraestructuras hidráulicas que se han ido analizando a lo largo del texto son una prueba de cómo la ingeniería romana resolvió la necesidad de agua que fue creciendo poco a poco a lo largo del imperio. El Ebro Medio es una buena muestra de ello puesto que todas las ciudades investigadas tenían alguna conducción para poder llevar agua a sus habitantes.

De los sistemas de captación sólo se han conservado las presas. Los métodos constructivos son diversos. La Degollada tiene una cimentación a modo de zapata de areniscas de pequeño tamaño que soporta un doble paramento de siIlares perfectamente encuadrados que aguardan un alma de opus caementicum. En Alfaro, la pantalla de El Sotillo es un muro de opus quadratum de arenisca asentados sobre una cimentación preparada a base de cantos de río mientras que El Burgo presenta un núcleo de cemento y un paramento de sillares cuyas juntas fueron selladas con una capa de argamasa ${ }^{89}$.

Los sistemas de conducción mediante acueductos también fueron heterogéneos. El más sencillo es sin duda es el de Vareia mediante un canal de piedra que se aclimataba a las curvas del terreno. Las canalizaciones de Calagurris

dad termal. Para más información ver Espinosa, U. y López, R., "Agua y cultura antigua... pp. 262-263.

85. Nynph(is)·et/bo·ni·s/et·lo·co·s(acrum·siue-acro) (Ciprés, P. y González, M. C., "Nueva lectura e interpretación del ara de Cabriana (Lantarón, Álava) dedicada a las Ninfas: HAEp 2531". Munibe. Antropología-Arkeologia 70 (2019), pp. 274-276).

86. V(otum)[·s(olvit)·l(ibens)·m(erito)]/ Nin[phis] (Elorza, J. C. y Abasolo, J. A., "Nuevos teónimos de época romana en el País Vasco-Navarro". Estudios de arqueología alavesa 6 (1974), pp. 250-251).

87. [Ca]pito·ar(am)/Nym[ph]is/[d(e)·s(uo)·p]osuit/[l]ibens·mer/ito (Elorza, J. C., "Ensayo topográfico de epigrafía... p. 127).

88. $F($ aciendum) $\cdot c($ uravit) $\cdot \mid($ ibenter) $\cdot \operatorname{Ninph}([$ is $] \cdot[\mathrm{de}] \cdot[\mathrm{p}] \mathrm{ec}[\mathrm{u} / \mathrm{nia} \cdot \mathrm{sua}] \quad$ (ERRioja, 32). Urbano Espinosa y Ramón López consideran esta lectura incorrecta y apuestan por que se plasmó el término Cluniensis (Espinosa, U. y López, R., "Agua y cultura antigua... p. 261).

89. Para más información sobre los sistemas constructivos, la tipología y la descripción de las presas de cronología romana de la península ibérica, especialmente, los ejemplares del Ebro ver Castillo, J. C. "Las presas romanas en España". Revista de Obras Públicas 3475 (2007), pp. 68-79. 
Iulia, tanto la de Alcanadre-Lodosa que daba servicio a su centuriación como el de la Sierra La Hez que surtía a la propia ciudad, son los que más soluciones constructivas tenían a lo largo de su recorrido incluyendo el uso de paramentos de piedra y hormigón para los canales y sistemas de arquerías para superar zonas deprimidas del terreno. Las dos conducciones que daban servicio a ambas civitates eran "compartidos" dado que su finalidad era principalmente el entorno urbano, pero no exclusivamente ya que también aportaban agua a otras industrias o establecimiento rurales ${ }^{90}$.

El conocimiento de los complejos termales depende en gran medida de su grado de conservación y de excavación. De esta manera, las termas de Andelos son los que más datos han aportado porque han sobrevivido con su planta completa. Calahorra destaca por las tres instalaciones que llegaron a convivir, aunque únicamente las de San Andrés han sido investigadas en un mayor grado ya que las "Termas del Norte" han sido excavadas de manera muy puntual o de urgencia. Estas es la misma situación de las piscinas de Vareia. Las rurales ofrecen un panorama muy diferente. De las que se han llegado a investigar (Liédena, Soto del Ramalete o Cabriana), se ha podido constatar un panorama muy completo donde convivían los tres ambientes a diferente temperatura con el tamaño necesario para integrarse en todo el complejo rural y el nivel económico de su propietario.

El agua era también fuente de riqueza. Desgraciadamente no se cuenta con infraestructuras de regadío comparables a los localizados en otros lugares de la península como puede ser el magnífico ejemplo de Los Marroquíes Bajos en Jaén ${ }^{91}$, las posibilidades que tiene el territorio adscrito jurídicamente a la capital conventual de Caesaraugusta ${ }^{92}$ o las zonas rurales del

90. Esta tipología era típica de las grandes conducciones que daban servicio a varios entornos urbanos siendo un ejemplo el acueducto de Serino en la zona de Nápoles (260-261). Los ejemplares de Varea y Calahorra tenían como principal función el abastecimiento a estas ciudades, pero articulaban la región y servían a establecimiento rurales, núcleos industriales y, en el caso calagurritano, regar la zona sur y suroeste de su centuriación (De la Peña, J. M., "Sistemas romanos de abastecimiento de aguas", Fundación de la Ingeniería Técnica de Obras Públicas, Las técnicas y las construcciones en la ingeniería romana. Actas del Congreso de Obras Públicas Romana. Córdoba 2010, pp. 260-261).

91. Se trata de uno de los ejemplos más representativos que han sido objeto de una excavación arqueológica. En su fase romana, al margen de los restos de un complejo de explotación tipo villa, destacan las infraestructuras de carácter hidráulico que se componen de canales, balsas o cisternas cuya cronología ocupa todo el periodo imperial, especialmente los dos primeros siglos de nuestra Era. Para más información ver Barba, V., Instalaciones hidráulicas en la zona arqueológica de Marroquíes Bajos (Jaén). Jaén 2007.

92. En este sector del valle del Ebro se cuenta con documentos jurídicos como el ya tratado Bronce de Agón o la Tabula Contrebiensis junto con indicios arqueológicos en el entorno del Jalón, el Huecha o la investigación de las acequias históricas (Ariño, E. "Sistemas de irrigación de época antigua en el territorio de Caesar Augusta (Zaragoza, España): testimonios epigráficos y evidencias arqueológicas". Saldvie, 11-12 (2011-2012), pp. 37-46). 
Camp de Tarragona ${ }^{93}$; pero la existencia de sistemas de captación como la Degollada o los complejos monumentales del entorno de Gracurris (Alfaro), el acueducto de Alcanadre-Lodosa o el Bronce jurídico de Agón (Aragón) abogan por la existencia de un entramado de canales para el cultivo de diferentes variedades verduras, hortalizas o frutales que han quedado como decoración en las piezas producidas en los complejos alfareros. Los usos industriales del agua están atestiguados en los diferentes alfares que se han excavado en el entorno de las ciudades, especialmente en las piletas de decantación. Pero también dentro de los entornos urbanos se utilizaba para las diferentes industrias que se desarrollaron en su interior como pueden ser las alimenticias.

La mayor parte de las infraestructuras hidráulicas se planificaron y se ejecutaron a lo largo de la segunda mitad del siglo I, especialmente aquellas que formaron parte del programa de monumentalización de las civitates del área de estudio. El mejor ejemplo se encuentra en Calagurris Iulia donde se realizó una ampliación urbana hacia el oeste con una cronología entre el final del periodo Julio-Claudio y el reinado de los primeros emperadores Flavio. El eje utilizado para esta nueva zona fue la orientación noreste-suroeste de la centuriación, especialmente evidente en el circo. Junto a este edificio de espectáculos se realizaron dos complejos termales: el de las Carretera de Arnedo destinadas al servicio de la calzada del Ebro y las del Norte. Estas termas fueron sufriendo remodelaciones ejemplificadas en estas últimas con reformas en el siglo II donde se produjeron mejoras y, con la construcción de la muralla bajoimperial, fueron reducidas en su extensión, pero siguieron en uso durante el siglo IV ${ }^{94}$. Las cloacas han dado materiales de cronología similar. Las infraestructuras hidráulicas vareyenses evolucionaron con la ciudad. Se pusieron en servicio tras la marcha de la legio IIII Macedonica y fueron abandonados en el siglo V, destacando las reformas o la reconstrucción de algunos elementos del sistema de distribución urbana $^{95}$.

El derecho y la religión también estuvieron relacionados con el agua en época romana. El Bronce de Agón es un excelente ejemplo sobre un documento jurídico para la regulación de una comunidad de regantes en los que intervenía el patrocinio público y los textos recogidos en el Digesto describen

93. Especialmente interesantes son las infraestructuras hidráulicas que se construyeron en las villae rurales donde era necesario una gran cantidad de agua para el desarrollo de las figlinae que fabricaban ánforas de transporte. Un estado de la cuestión se puede encontrar en Prieto, A., Arrayás, I. y López, M. J., "Sobre los sistemas de regadío en época romana: el caso del territorio de Tarragona y Almería", Lagóstena, Cañizar y Pons, Aqvam·perdvcendam·cvravit. Captación, uso y administración del agua en las ciudades de la Bética y el Occidente Romana. Cádiz 2011, pp. 385-389.

94. Vid supra notas 33 a 39.

95. Vid supra notas 29 a 32. 
la protección de los ríos y sus riberas mientras que las leyes municipales daban la posibilidad de construir y mantener los canales públicos de las ciudades. La protección de los cursos fluviales fomentaba su uso comercial como puede ser su navegabilidad.

La búsqueda de protección también se buscaba mediante la petición a la divinidad, en este caso, a las que residían en las aguas o mediante el uso del agua para poder comunicarse con las Ninfas. Disponemos de varios testimonios epigráficos, pero también de centros de culto construidos a tal efecto en esos dos conjuntos monumentales que se edificaron en Alfaro junto al río Alhama. Un pequeño templete y un lacus en El Sotillo y una fuente sagrada que manaba del interior de la exedra a modo de ninfeo en El Burgo.

Por lo tanto, podemos hablar de un ciclo artificial del agua en época romana que, como hoy en día, posibilitaba que los habitantes de las ciudades o de las unidades de población rural dispusieran de agua para su consumo, su disfrute y su aprovechamiento económico. Un líquido que posibilitaba la comunicación con los dioses, su intersección y que era objeto de protección y regulación mediante documentos jurídicos.

Tabla1. Resumen con las infraestructuras hidráulicas mencionadas en el texto. Elaboración propia.

\begin{tabular}{|l|l|l|l|l|}
\hline \multicolumn{1}{|c|}{ Denominación } & \multicolumn{1}{|c|}{ Lugar } & \multicolumn{1}{|c|}{ Tipología } & \multicolumn{1}{c|}{ Cronología } & \multicolumn{1}{|c|}{ Bibliografía } \\
\hline La Degollada & Calahorra & $\begin{array}{l}\text { Presa para } \\
\text { regadío }\end{array}$ & Siglos I-IV & Cinca, 2012. \\
\hline El Sotillo & Alfaro & $\begin{array}{l}\text { Presa-puente- } \\
\text { ninfeo }\end{array}$ & $\begin{array}{l}\text { Segunda mitad I a.C.- } \\
\text { finales I d. C. }\end{array}$ & $\begin{array}{l}\text { Hernández et al., } \\
1999 .\end{array}$ \\
\hline El Burgo & Alfaro & $\begin{array}{l}\text { Presa-puente- } \\
\text { ninfeo }\end{array}$ & Finales siglo I- IV/V & $\begin{array}{l}\text { Hernández et al., } \\
1998 .\end{array}$ \\
\hline $\begin{array}{l}\text { Acueducto de la } \\
\text { Sierra La Hez }\end{array}$ & $\begin{array}{l}\text { Ocón- } \\
\text { Arnedo- }\end{array}$ & $\begin{array}{l}\text { Acueducto } \\
\text { Compartido }\end{array}$ & Segunda mitad del I-IV & Pascual, 1991. \\
\hline $\begin{array}{l}\text { Acueducto de } \\
\text { Vareia }\end{array}$ & Logroño & $\begin{array}{l}\text { Acueducto } \\
\text { compartido }\end{array}$ & Segunda mitad del I-V & $\begin{array}{l}\text { Martínez y Galle, } \\
1994 .\end{array}$ \\
\hline $\begin{array}{l}\text { Acueducto } \\
\text { Alcanadre-Lodosa }\end{array}$ & $\begin{array}{l}\text { Mendavia- } \\
\text { Lodosa- } \\
\text { Calahadre- }\end{array}$ & $\begin{array}{l}\text { Acueducto } \\
\text { rural }\end{array}$ & Siglos II-IV/V & Mezquíriz, 2004b. \\
\hline $\begin{array}{l}\text { Distribución } \\
\text { urbana Vareia }\end{array}$ & Logroño & Fuentes & Segunda mitad del I-V & $\begin{array}{l}\text { Martínez y Gallego, } \\
1994 .\end{array}$ \\
\hline $\begin{array}{l}\text { Distribución } \\
\text { urbana de } \\
\text { Calagurris }\end{array}$ & Calahorra & $\begin{array}{l}\text { Conducciones } \\
\text { y cloacas }\end{array}$ & Segunda mitad del I-V & $\begin{array}{l}\text { Luezas y Andrés, } \\
\text { Cinca, 2002. } \\
\text { Cinca, 2011. } \\
\text { Gil y Luezas, 2012. } \\
\text { Ramos, 2015. }\end{array}$ \\
\hline
\end{tabular}




\begin{tabular}{|c|c|c|c|c|}
\hline Denominación & Lugar & Tipología & Cronología & Bibliografía \\
\hline $\begin{array}{l}\text { Distribución } \\
\text { urbana de } \\
\text { Graccurris }\end{array}$ & Alfaro & $\begin{array}{l}\text { Conducciones } \\
\text { y fuente }\end{array}$ & Segunda mitad del I-IV & Martínez, 1993. \\
\hline Termas de Vareia & Logroño & $\begin{array}{l}\text { Complejo } \\
\text { termal urbano }\end{array}$ & Segunda mitad del I-IV & $\begin{array}{l}\text { Martínez y Gallego, } \\
1994 . \\
\text { Cabada et al., } 1997 . \\
\text { Heras y Bastida, } \\
1999 .\end{array}$ \\
\hline Termas del Norte & Calahorra & $\begin{array}{l}\text { Complejo } \\
\text { termal urbano }\end{array}$ & Segunda mitad del I-V & $\begin{array}{l}\text { Luezas, } 1998 . \\
\text { Luezas, } 2000 . \\
\text { Tirado, } 2000 .\end{array}$ \\
\hline $\begin{array}{l}\text { Termas de San } \\
\text { Andrés }\end{array}$ & Calahorra & $\begin{array}{l}\text { Complejo } \\
\text { termal urbano }\end{array}$ & Segunda mitad del I-V & $\begin{array}{l}\text { Luezas, } 2000 . \\
\text { Iguacel, } 2002 . \\
\text { Cinca, } 2011 .\end{array}$ \\
\hline $\begin{array}{l}\text { Termas de la } \\
\text { Carretera de } \\
\text { Arnedo }\end{array}$ & Calahorra & $\begin{array}{l}\text { Complejo } \\
\text { termal urbano }\end{array}$ & Segunda mitad del I-IV & Luezas, 2000. \\
\hline Termas de Andelos & Mendigorría & $\begin{array}{l}\text { Complejo } \\
\text { termal urbano }\end{array}$ & Segunda mitad del I-IV & Mezquíriz, 2009a. \\
\hline Termas de Liédena & Liédena & $\begin{array}{l}\text { Complejo } \\
\text { termal rural }\end{array}$ & $\begin{array}{l}\text { Segunda mitad del I/ } \\
\text { II-V }\end{array}$ & $\begin{array}{l}\text { Taracena, } 1950 . \\
-M e z q u i ́ r i z, 2000 b .\end{array}$ \\
\hline $\begin{array}{l}\text { Termas de Soto del } \\
\text { Ramalete }\end{array}$ & Tudela & $\begin{array}{l}\text { Complejo } \\
\text { termal rural }\end{array}$ & Siglos III-V & Mezquíriz, 2009b. \\
\hline $\begin{array}{l}\text { Termas de } \\
\text { Cabriana }\end{array}$ & $\begin{array}{l}\text { Lantarón/ } \\
\text { Miranda de } \\
\text { Ebro }\end{array}$ & $\begin{array}{l}\text { Complejo } \\
\text { termal rural }\end{array}$ & Siglos II-V & $\begin{array}{l}\text { Ortiz de Urbina y } \\
\text { Pérez, } 1990 .\end{array}$ \\
\hline Baños de Fitero & Fitero & $\begin{array}{l}\text { Complejo } \\
\text { termal natural }\end{array}$ & Siglos II-actualidad & $\begin{array}{l}\text { Mezquíriz, 2004b. } \\
\text { Pérex y Martín, } 2018 .\end{array}$ \\
\hline $\begin{array}{l}\text { Canalización de } \\
\text { alfar del Najerilla }\end{array}$ & Tricio & $\begin{array}{l}\text { Conducción } \\
\text { industrial }\end{array}$ & Siglos I-II & $\begin{array}{l}\text { Alonso de Medina, } \\
2001 . \\
\text { Alonso, } 2015 .\end{array}$ \\
\hline $\begin{array}{l}\text { Canalización del } \\
\text { alfar de La Maja }\end{array}$ & $\begin{array}{l}\text { Calahorra/ } \\
\text { Pradejón }\end{array}$ & $\begin{array}{l}\text { Conducción } \\
\text { industrial }\end{array}$ & Siglos I-III & $\begin{array}{l}\text { González, } 1996 . \\
\text { Luezas, } 2011 .\end{array}$ \\
\hline $\begin{array}{l}\text { Molinos } \\
\text { hidráulicos }\end{array}$ & $\begin{array}{l}\text { Cuenca del } \\
\text { Leza }\end{array}$ & $\begin{array}{l}\text { Maquinaria } \\
\text { industrial }\end{array}$ & Contexto bajoimperial & $\begin{array}{l}\text { Pascual y García, } \\
2001 .\end{array}$ \\
\hline $\begin{array}{l}\text { Infraestructuras } \\
\text { hidráulicas en } \\
\text { la villa de "Los } \\
\text { Ladrillos" }\end{array}$ & Tirgo & $\begin{array}{l}\text { Establecimiento } \\
\text { rural }\end{array}$ & Siglos I-IV & Porres, 2000. \\
\hline
\end{tabular}

\section{Bibliografía}

Alonso, C., Nuestra Señora de Arcos (Tricio, La Rioja) de basílica a ermita a la luz de la arqueología. Logroño 2015.

Alonso de Medina, I., "Sondeos realizados en la finca urbana de Arcos (Tricio)". Estrato 13 (2001), pp. 55-60. 
Ariño, E., "Sistemas de irrigación de época antigua en el territorio de Caesar Augusta (Zaragoza, España): testimonios epigráficos y evidencias arqueológicas". Saldvie 11-12 (2011-2012), pp. 35-48.

Ariño, E., Hernández, J. A., Martínez, J. N. y Nuñez, J., "Graccurris: conjuntos monumentales en la periferia urbana: puentes, presas y ninfeos". Graccurris 4 (1995), pp. 21-265.

Ariño, E. y Magallón, M. Á., "Problemas de trazado de las vías romanas en la provincia de La Rioja". Zephyrus 44-45 (1991-1992), pp. 423-455.

Armendáriz, J. y Velaza, J., "Nueva ara romana de Barbarin (Navarra)". Sylloge Epigraphica Barcinonensis 4 (2002), pp. 47-50.

Barba, V., Instalaciones hidráulicas en la zona arqueológica de Marroquíes Bajos (Jaén). Jaén 2007.

Beltrán, F. y Willi, A., "El regadío en la Hispania Romana. Estado de la cuestión". Cuadernos de prehistoria y arqueología de la Universidad de Granada 21 (2011), pp. 9-56.

Cabada, J. J., Tirado, J. A., Heras, C. M., Andrés, S., "Estructuras termales en la ciudad romana de Vareia (Logroño, La Rioja)", Pérex, Termalismo antiguo. I Congreso peninsular. Arnedillo (La Rioja). 3-5 de Octubre de 1996. Madrid 1997, pp. 419-426.

Castillo, J. C., "Las presas romanas en España". Revista de Obras Públicas 3475 (2007), pp. 65-80.

Castillo, M. J., "Ríos y calzadas en el valle del Ebro: la influencia de la navegación en el trazado de las vías", Czeguhn, Waser, wege, wissen auf der iberischen halbinselvom Römischen Imperium bis zur islamischen Herrschaft. Nomos 2016, pp. 47-72.

Cinca, J. L., "La red de saneamiento", Iguácel, Pavía, Cinca, y Castillo, Así era la vida en una ciudad romana: Calagurris Iulia. Calahorra 2002, pp. 61-72.

Cinca, J. L., "Urbanismo y obras públicas en el Alto Imperio", Castillo, Espinosa, Cinca, Luezas, Gómez, y Barenas, "Edad Antigua", Cinca, y González, Historia de Calahorra. Calahorra 2011, pp. 94-108.

Cinca, J. L., "La presa romana de La Degollada (Calahorra, La Rioja)". Kalakorikos 17 (2012), pp. 331-354.

Ciprés, P. y González, M. C., "Nueva lectura e interpretación del ara de Cabriana (Lantarón, Álava) dedicada a las Ninfas: HAEp 2531". Munibe. Antropología-Arkeologia 70 (2019), pp. 271-283.

De la Peña, J. M., "Sistemas romanos de abastecimiento de aguas", Fundación de la Ingeniería Técnica de Obras Públicas, Las técnicas y las construcciones en la ingeniería romana. Actas del Congreso de Obras Públicas Romana. Córdoba 2010, pp. 249-282.

D'Ors, A. y D'Ors, J., "Lex Irnitana. Texto bilingüe". Cuadernos compostelanos de Derecho Romano 1 (1988). 
Elorza, J. C., "Ensayo topográfico de epigrafía romana alavesa". Estudios de arqueología alavesa 2 (1967), pp. 119-185.

Elorza, J.C. y Abasolo, J. A., "Nuevos teónimos de época romana en el País Vasco-Navarro". Estudios de arqueología alavesa 6 (1974), pp. 247-258.

Espinosa, U., Epigrafía romana de La Rioja. Logroño 1986.

Espinosa, U. y López, R., "Agua y cultura antigua en el alto-medio Ebro", Pérez (ed.), Termalismo antiguo Actas del I Congreso Penínsular. Arnedillo (La Rioja). 3-5 de Octubre de 1996. Madrid 1997, pp. 259-265.

Filloy, I., "Viña Assa (Lanciego)". Arkeoikuska: investigación arqueológica 1998 (1998), pp. 208-211.

Luezas, R. A., "Arqueología urbana de Calahorra". Estrato. Revista riojana de arqueología 9 (1998), pp. 24-34.

Luezas, R. A., "Termas romanas en el Municipium Calagurris lulia (Calahorra, La Rioja)", Fernández y García, II Coloquio Internacional de Arqueología de Gijón. Termas romanas en el Occidente del Imperio (Gijón 1999). Gijón 2000, pp. 185-192.

Luezas, R. A., "Manifestaciones artísticas en Calagurris Iulia", Castillo, Espinosa, Cinca, Luezas, Gómez y Barenas, "Edad Antigua", Cinca y González, Historia de Calahorra. Calahorra 2011, pp. 115-130.

Luezas, R. A. y Andrés, G., "Calahorra. Obras hidráulicas en el municipium Calagurris lulia". Estrato. Revista riojana de arqueología 10 (1999), pp. 25-32.

Gil, L. y Luezas, R. A., "Intervenciones arqueológicas en varios solares del entorno del centro comercial ARCCA de Calahorra (La Rioja) II". Kalakorikos 17 (2012), pp. 355-406.

González, A., "El alfar de La Maja adquiere dimensiones insospechadas. Campaña de julio de 1995". Estrato 7 (1996), pp. 49-64.

González, A., "El alfar romano de La Maja (Pradejón-Calahorra, La Rioja). Informe de la campaña de 1996: prosigue la reconstrucción de la oficina de G. Valerio Verdullo". Estrato 8 (1997), pp. 23-33.

Heras, C. M. y Bastida, A. B., "Arquitectura romana de Varea: el conjunto termal". Estrato: revista riojana de arqueología 10 (1999), pp. 60-72.

Hernández, J. A., Ariño, E., Martínez, J. M. y Nuñez, J., "Contribución al estudio de las presas y ninfeos hispanos: el conjunto monumental del Burgo (Alfaro, La Rioja)". Zephirus: revista de prehistoria y arqueología 51 (1998), pp. 219236.

Hernández, J. A., Ariño, E., Martínez, J. M. y Nuñez, J., "La presa y el ninfeo del Sotillo (Alfaro, La Rioja): un conjunto monumental en la De Italia in Hispanias". Zephyrus: revista de prehistoria y arqueología 52 (1999), pp. 239-260.

Iguácel, P., "El trazado urbano", Iguácel, Pavía, Cinca y Castillo, Así era la vida en una ciudad romana: Calagurris Iulia. Calahorra 2002, pp. 39-50. 
Martínez, J. M., "Excavaciones arqueológicas en las Eras de la Cárcel". Estrato. Revista riojana de Arqueología 5 (1993), pp. 23-26.

Martínez, J. M. y Del Fresno, P., Evolución del poblamiento altomedieval de las Eras de San Martín. Síntesis de los Resultados de las campañas 2000 a 2005. Alfaro, Graccurris. Equipo de investigación arqueológica 2006, p. 11. Recuperado de internet <http://www.graccurris.info/gr/index.php/es/informes-2006>. (Consultado 09/12/2018)

Martínez, J. y Gallego, R., "II. Vareia en el universo romano: de la sumisión a la integración. 5. Morfología del enclave vareyense", Espinosa, "Vol. 1: Antigüedad", Sesma, Historia de la Ciudad de Logroño. Logroño 1994, pp. 159-178.

Martínez, J. M. y Jordán, C., "Una tésera celtibérica y algunas inscripciones sobre instrumentum procedentes de Graccurris (Alfaro, La Rioja)". Paleohispanica 16 (2016), pp. 261-279.

Mezquíriz, M. A., "El acueducto de Alcanadre-Lodosa". Trabajos de arqueología Navarra 17 (2004a), pp. 253-272.

Mezquíriz, M. A., "Las termas romanas de Fitero". Trabajos de arqueología Navarra 17 (2004b), pp. 273-286.

Mezquíriz, M. A., Andelo. Ciudad romana. Pamplona 2009a.

Mezquíriz, M. A., "Las "villae" tardorromanas del Valle del Ebro". Trabajos de arqueología navarra 21 (2009b), pp. 199-272.

Mezquíriz, M. A. y Unzu, M., "Presencia de un aquilegus en Leire. Posible sustrato romano". Trabajos de arqueología Navarra 15 (2001), pp. 157-166.

Ortiz de Urbina, C. y Pérez, E., "El inicio de la arqueología en Álava: D. Lorenzo de Prestamero y Cabriana". Veleia 1 (1990), pp. 105-118.

Pascual, P. y García, P., "Canteras y tecnología molinar en el río Jubera (La Rioja)". Revista Murciana de Antropología 7 (2001), pp. 237-266.

Pascual, M. P., "Abastecimiento de agua a Calagurris", Arqueología de Calahorra: miscelánea. Calahorra 1991, pp. 53-104.

Pascual, M. P. y García, P., "El abastecimiento de agua", Iguácel, Pavía, Cinca y Castillo, Así era la vida en una ciudad romana: Calagurris Iulia. Calahorra 2002, pp. 51-60.

Pérex, M. J. y Martín, C., "Aguas termales y mineromedicinales en el valle del Ebro. Su incidencia en el poblamiento en época romana", Castillo e Iguácel, Studia Histórica in Honorem Prof. Urbano Espinosa Ruiz. Logroño 2018, pp. 179-204.

Porres, F., "Tirgo. El yacimiento romano de 'Los Ladrillos'. Estudio de los materiales". Estrato 12 (2000), pp. 49-53.

Prieto, A., Arrayás, I. y López, M. J., "Sobre los sistemas de regadío en época romana: el caso del territorio de Tarragona y Almería", Lagóstena, Cañizar 
y Pons, Aqvam·perdvcendam·cvravit. Captación, uso y administración del agua en las ciudades de la Bética y el Occidente Romana. Cádiz 2011, pp. 383-396.

Ramos, M., "Seguimiento arqueológico de la urbanización del Planillo de San Andrés (Calahorra, La Rioja)". Kalakorikos 20 (2015), pp. 103-125.

Santos, J. y Calonge, A., "El entramado viario romano en el norte de La Rioja. Sobre la calzada paralela al Ebro (Logroño-Cihuri)", Castillo e Iguácel, Studia Historica in Honoren Prof. Urbano Espinosa Ruiz. Logroño 2018, pp. 205232.

Taracena, B., "Excavaciones en Navarra. La villa romana de Liédena. Capítulo II". Príncipe de Viana 37 (1950), pp. 9-40.

Tirado, J. A., El yacimiento del Solar Torres: niveles de ocupación prerromanos y romanos. Calahorra 2000.

Tudanca, J. M. y López de Calle, C., "Al otro lado del espejo. Vareia. 465 A.D.", Tejado (coord.), Vislumbrando la tardoantigüedad: una mirada desde la arqueología. Logroño 2018, pp. 41-69. 